\title{
Legal Institutions, Sectoral Heterogeneity, and Economic Development*
}

\author{
Rui Castro ${ }^{\dagger} \quad$ Gian Luca Clementi ${ }^{\ddagger} \quad$ Glenn MacDonald ${ }^{\S}$
}

September 21, 2006

\begin{abstract}
A large body of evidence suggests that poor countries tend to invest less (have lower PPP-adjusted investment rates) and to face higher relative prices of investment goods. It has been suggested that this happens either because these countries have lower TFP in the investment-good producing sectors, or because they are subject to greater investment distortions. What is still to be understood, however, is what are the causes of these shortcomings. In this paper we address this question by providing a micro-foundation for the cross-country dispersion in investment distortions. Our analysis rests on two premises: 1) countries differ with respect to the rights enjoyed by outside investors (such as bondholders and minority shareholders) and 2) firms producing capital goods face a higher level of idiosyncratic risk than their counterparts producing consumption goods. In a model of capital accumulation where the protection of investors' rights is incomplete, this difference in risk induces a wedge between the returns on investment in the two sectors. The wedge is bigger, the lower the investor protection. In turn, this implies that countries endowed with weaker institutions are poorer, face higher relative prices of investment goods, and invest a lower fraction of their income. Our analysis also suggests that the mechanism we study may be quantitatively important.
\end{abstract}

Key words. Macroeconomics, Investment Rate, Overlapping Generations, Relative Prices, Investor Protection, Optimal Contracts.

JEL Codes: E22, F43, G32, G38, O16, O17, O41.

${ }^{*}$ We thank George Alessandria, Francesco Caselli, Daniele Coen-Pirani, Sílvia Gonçalves, Sebnem Kalemli-Ozcan, Pat Kehoe, Lubomir Litov, Rody Manuelli, Sarah McVay, Lee Ohanian, Benoit Perron, Thomas Philippon, Richard Rogerson, Fabiano Schivardi, Bob Shimer, and Gianluca Violante, as well seminar attendants at Bologna, Carlos III, Ente Einaudi, EUI (Florence), HEC Lausanne, HEC Montréal, Houston, INSEAD, UMontréal, NYU, Queen's, UT Austin, the 2006 SOEGW Conference in Rimini, the 2006 Economic Development Conference at Arizona State, the 2005 NBER Summer Institute, the 2005 ITAM Macro Summer Camp, the 2005 Canadian Macro Study Group in Vancouver, the 2005 Midwest Macro Meeting in Iowa City, the 2005 ES World Meeting in London, the 2005 EEA meeting in Amsterdam, the 2005 CEA conference in Hamilton, the 2005 SCSE conference in Charlevoix, the 2004 SED Meeting in Florence, and the 2004 International Macro Conference at the Cleveland Fed, for their comments and suggestions. All remaining errors are our own responsibility. We are specially grateful to Nelnan Koumtingué for outstanding research assistance. Castro acknowledges financial support from the SSHRC (Canada) and the FQRSC (Québec). Clementi thanks CIREQ and the Department of Economics at the Université de Montréal for their generous hospitality at various stages of this project.

${ }^{\dagger}$ Department of Economics and CIREQ, Université de Montréal. Email: rui.castro@umontreal.ca. Web: http://www.fas.umontreal.ca/sceco/castroru

${ }^{\ddagger}$ Department of Economics, Stern School of Business, New York University. Email: clem@nyu.edu. Web: http://pages.stern.nyu.edu/ gclement

${ }^{\S}$ Olin School of Business, Washington University in St.Louis. Email: macdonald@wustl.edu. Web: http://www.olin.wustl.edu/faculty/macdonald.html 


\section{Introduction}

This paper is about understanding why per-capita income co-varies positively with the $\mathrm{PPP}$-adjusted investment rate and negatively with the the relative price of capital goods. Our main conclusion is that cross-country differences in the quality of legal institutions can account for a large fraction of the observed variation in prices and investment rates.
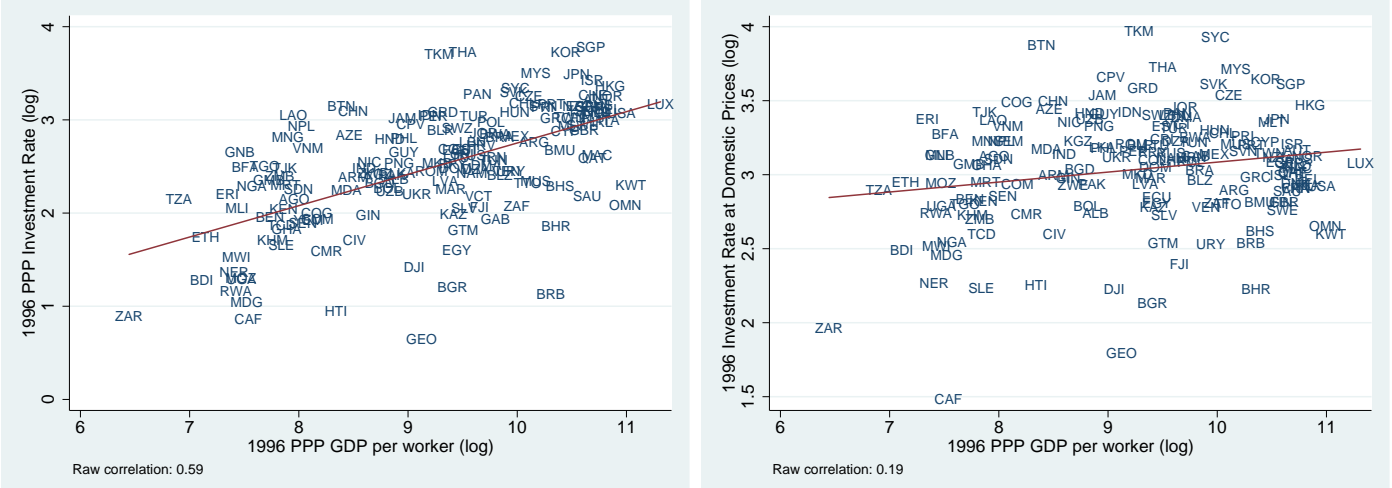

Figure 1: Investment Rates and Income Levels.

Heston and Summers $(1988,1996)$ first emphasized that the behavior of investment rates in the cross-section of countries depends on the prices used to compute them. When capital goods are valued using international prices, investment rates covary positively with income. However, when domestic prices are used, this positive association disappears: investment rates do not seem to covary with income. These features of the data are documented in Figure 1, which was constructed using data from Heston, Summers, and Aten's (2002) Penn World Table, version 6.1. A third fact, also reported by De Long and Summers (1991), Easterly (1993), and Jones (1994), and documented in Figure 2, is that the relative price of investment goods with respect to consumption goods is negatively correlated with income. ${ }^{1}$ These observations suggest that rich and poor countries devote similar fractions of their incomes to investment expenditures, but the former obtain a higher yield in terms of capital goods.

The economic development literature has produced two closely related rationalizations for the evidence we have just described. Hsieh and Klenow (2003) argue that

\footnotetext{
${ }^{1}$ The series of relative prices was constructed using the price indexes for consumption and investment goods reported in the Penn World Table 6.1. The methodology followed in constructing these indexes is outlined in Heston and Summers (1991) and in the technical documentation available at http://pwt.econ.upenn.edu/
} 


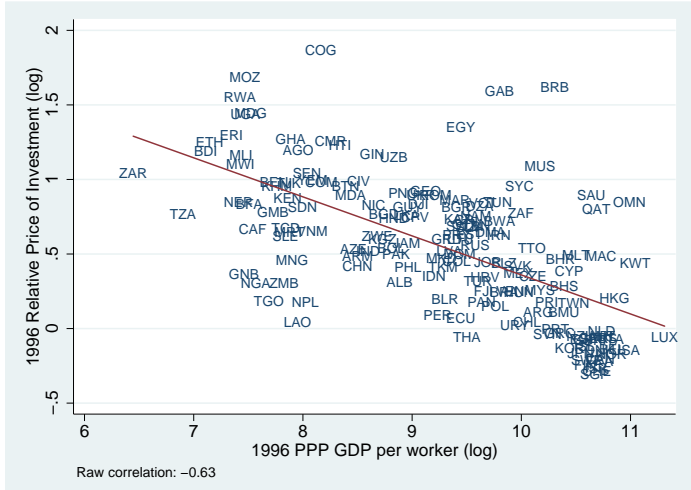

Figure 2: Relative price of Investment Goods and Income Levels.

poor countries may have lower investment rates simply because they are relatively more efficient in the production of consumption goods. This would make investment goods relatively more expensive, thereby lowering PPP investment rates. According to Chari, Kehoe, and McGrattan (1996) and Restuccia and Urrutia (2001), it is the variation in a generic form of investment distortion (wedge) that accounts for the evidence. Both of these mechanisms are quite successful, in the sense that cross-country differences in relative sectoral TFP or in investment wedges, when calibrated to match the variation in prices in a neoclassical growth model, also generate a sizeable variation in investment rates. The next challenge is to understand the origin of either form of cross-country heterogeneity (in relative TFP or in wedges). This is crucial, if we entertain any ambition to suggest policies that may help poor countries develop at a faster pace. In this paper, we provide a micro-foundation for the variation in distortions and we evaluate its economic significance.

In our model, countries employ the same technologies. They differ, however, in the extent to which the commercial law and its enforcement protect outside investors, such as bondholders and minority shareholders, from expropriation by company insiders. Several recent papers, among which La Porta, Lopez-de Silanes, Shleifer, and Vishny (1998), provide evidence in support of the hypothesis that investor protection differs greatly across countries. The other crucial assumption is that firms producing investment goods face higher baseline idiosyncratic risk than firms producing consumption goods. In Section 2 we show that data drawn from COMPUSTAT Files for the United States provide strong support for this hypothesis. Even after controlling for a set of observable characteristics and for unobserved heterogeneity, companies producing capital goods display a much higher volatility of sales growth. To our knowledge, this is a novel result. 
Ours is a fairly standard two-sector overlapping generation model of capital accumulation. The two sectors produce investment goods and consumption goods, respectively. Each individual is born endowed with entrepreneurial talent and decides whether to allocate it to the production of investment or consumption goods. Regardless of his choice, he will have access to a technology displaying decreasing returns to capital. The output outcome is stochastic, i.i.d. across technologies, and known only to the technology's owner. The only difference across sectors is that cash flows are more volatile in the case of firms producing investment goods. Young individuals, who we refer to as entrepreneurs, borrow capital from the old through financial intermediaries. The interaction between entrepreneurs and intermediaries takes the familiar form of an optimal contracting problem under asymmetric information. The optimal contract trades off risk-sharing and incentive provision. We model institutions by assuming that entrepreneurs who misreport their outcomes and hide resources face a deadweight loss. The magnitude of this loss reflects the effectiveness of all institutional features that protect outside investors from expropriation by company insiders. The larger the loss, the better the investor protection (the quality of institutions).

The optimal contract dictates that in either sector risk-sharing is increasing in the level of investor protection and decreasing in the volatility of cash flows. Given our assumption on the cross-sectoral variation in volatility, this implies a wedge between the returns to investment in the consumption and in the investment good sector. The size of this wedge is larger, the poorer the investor protection. In turn, this implies that the relative price of capital goods is decreasing in the level of investor protection. National income and the investment rate are also shown to be increasing in the quality of the legal system. This happens because the wedge between the rates of return on investment in the two sectors induces an allocative inefficiency, whose magnitude depends negatively on the level of investor protection.

Our main conclusion is that differences in the quality of the legal system can generate a correlation pattern between income level, the relative price of capital goods, and the investment rate, which is qualitatively in line with the data. Our analysis also hints that the mechanism we focus upon may be quantitatively important. A version of our model, parameterized in order to be consistent with the observed dispersion in relative investment prices, accounts for about one half of the standard deviation in investment rates implied by the 1996 Penn World Table.

We see our paper as contributing to the research program in economic development. The development literature started out by assuming that investment rates are exogenous (see Mankiw, Romer, and Weil (1992)). Chari, Kehoe, and McGrattan 
(1996) and Restuccia and Urrutia (2001) went further, arguing that the cross-country variation in both investment rates and relative prices may be the result of distortions in investment activity. The next step is to understand the nature of such distortions. Hsieh and Klenow (2003) conclude that taxes or tariffs on investment goods are not likely to be the answer, as they generate the counterfactual implication that investment goods' absolute prices correlate negatively with income per worker. ${ }^{2}$ In this paper, we assess whether the heterogeneity in distortions can be due to the combined effect of cross-country differences in legal institutions and cross-sectoral differences in idiosyncratic risk.

Our paper is closely related to recent contributions by Caselli and Gennaioli (2003), Restuccia and Rogerson (2003), Castro, Clementi, and MacDonald (2004), Restuccia (2004), Erosa and Hidalgo-Cabrillana (2004), Burstein and Monge-Naranjo (2005), and Guner, Ventura, and Yi (2005). In common with these authors, we investigate the implications of allocative inefficiencies for economic development. Our paper is closest to Castro, Clementi, and MacDonald (2004) and Erosa and HidalgoCabrillana's (2004). As is the case here, in these papers the allocative inefficiency is the result of information asymmetries in financial markets, and its magnitude depends on the quality of institutions designed to protect investors. Finally, our paper is also part of a recent literature that models investor protection in general equilibrium. ${ }^{3}$

The remainder of this paper is organized as follows. In Section 2 we provide evidence in support of our assumption on the cross-sectoral variation of cash flow volatility. We introduce the model in Section 3. In Section 4 we define and characterize the competitive equilibrium allocation. In particular, we derive the relation between investor protection and the relative price. In Section 5 we generalize the model in order to render it better suited for quantitative analysis, and we propose a calibration procedure. Section 6 is dedicated to comparative statics exercises. We show that, according to our model, countries with weaker institutions have lower income and lower investment rate. In Section 7 we allow for trade and for international capital flows. In Section 8 we assess whether our model can account for the variation in investment rates that emerges from the data. Finally, in Section 9 we discuss a few extensions of our setup. We argue that the mechanism at the core of our theory can

\footnotetext{
${ }^{2}$ According to Hsieh and Klenow (2003), the cross-country correlation between per-capita income and relative price of investment only reflects the variation in the absolute prices of consumption goods, which tend to be lower in poor countries. Eaton and Kortum (2001) make the same observation.

${ }^{3}$ Shleifer and Wolfenzon (2002) study the effect of investor protection on the size of the equity market and the number of public firms. Fabbri (2004) extends this analysis to consider the impact of the quality of legal institutions on firm size and aggregate activity. Albuquerque and Wang (2004) look at the asset pricing implications.
} 
have farther reaching implications than the ones we emphasized in this paper. Section 10 concludes.

\section{Evidence on Firm-Level Volatility}

In this section we provide evidence in support of our premise that firms in the investment good sector face higher baseline idiosyncratic risk than firms in the consumption good sector. For reasons that will become clearer in Section 3, we are interested in assessing the fraction of risk that is not accounted for by factors that would be known to a firm's financier. Among these factors, some are also observable to the econometrician: size and age; others, such as firm-specific characteristics and sector-specific shocks, are not. Our objective is to test whether in the case of firms producing investment goods the conditional standard deviation of sales is systematically higher than in the case of firms producing consumption goods.

Our dataset is an unbalanced panel of 8,078 firms, distributed in 60 3-digit NAICS sectors. It consists of a total of 81,454 firm-year observations, drawn from Standard \& Poor's COMPUSTAT North-America Industrial Annual Database from 1950 to 2005. Our sample selection procedure is detailed in Appendix A. We classify industries as consumption or investment good producing, based on the final destination of their output. The Bureau of Economic Analysis' Benchmark Input-Output tables provide information on the contribution of each industry to consumption and investment final demand uses. We classify an industry as a consumption good sector, say, if the ultimate destination of a sufficiently large share of its output is final consumption. We use an analogous rule to assign industries to the investment good category, and we discard sectors with very similar contributions to either final use. ${ }^{4}$

Our measure of sales is Compustat item \# 12, net sales. We first compute the portion of sales growth that is not accounted for by factors, either known or unknown to the econometrician, that are systematically associated with firm growth. We accomplish this task by estimating the following equation:

$$
\Delta \ln (\text { sales })_{i j t}=\alpha_{i}+\delta_{j t}+\beta_{1 j} \ln (\text { size })_{i j t}+\beta_{2 j} \ln (\text { age })_{i j t}+\varepsilon_{i j t} .
$$

The dependent variable is the growth rate of real sales for firm $i$ in sector $j$, between years $t$ and $t+1$. Real sales are net sales over the BEA's 2-digit sector-specific price deflator for value added. The dummy variable $\alpha_{i}$ is a firm-specific fixed effect that

\footnotetext{
${ }^{4}$ The estimates reported in Table 3 in Appendix A indicate that consumption sectors that according to common wisdom are more likely to produce durables behave much like investment good sectors. Unfortunately, the I-O tables do not break down consumption expenditures into durables and non-durables.
} 
accounts for unobserved heterogeneity across firms, i.e. for the eventuality that firms have permanently different growth rates for reasons that are unknown to us. ${ }^{5} \mathrm{We}$ also include a full set of sector-specific year dummies, denoted by $\delta_{j t}$. These dummies offer a flexible way to control for changes in sales induced by a variety of sector-wide factors. These include, but are not limited to, sector-specific shocks like weather shocks, changes in the economy's product mix, and business cycle fluctuations, which tend to have a systematically different impact on different sectors. In particular, investment expenditures are well-known to be much more volatile than consumption expenditures at the business cycle frequency (see for example Kydland and Prescott (1990)). Finally, size and age are included because the empirical Industrial Organization literature has shown that firm growth declines systematically with both of these variables (see Evans (1987) and Hall (1987)). Size is Compustat item \# 29, employees, whereas age is the time since a firm first appeared in the sample. ${ }^{6,7}$

The OLS estimates are reported in Table 4 in Appendix A. Our results are consistent with the well known findings that firm growth is decreasing in both age and size. The objects of our interest, however, are the residuals $\hat{\varepsilon}_{i j t}$. The idea is to use them to test for systematic differences in conditional volatility across sectors. The null hypothesis is that $\operatorname{var}\left(\varepsilon_{i j t}\right)$ is the same for firms belonging to consumption and investment good sectors. The Breusch-Pagan test rejects it categorically at the conventional significance level. ${ }^{8}$

Next, we would like to understand whether the test's result is driven by a small number of large and very volatile investment good sectors, or whether it is the consequence of a more general tendency. To this end, we estimate the following equation: ${ }^{9}$

$$
\ln \hat{\varepsilon}_{i j t}^{2}=\theta_{j}+u_{i j t}
$$

Letting $\hat{\theta}_{j}$ denote the point estimate of the dummy coefficient $\theta_{j}, \sqrt{\exp \left(\hat{\theta}_{j}\right)}$ is our

\footnotetext{
${ }^{5}$ In the benchmark version of our model, we abstract from ex-ante firm-level heterogeneity. In Section 9 and Appendix D we discuss some of the possible implications of incorporating it in our analysis.

${ }^{6}$ The number of employees is the most common measure of firm size in the empirical IO literature. Its main advantage is that it is relatively immune to measurement problems.

${ }^{7}$ In Section 3 we elect to model firm-level stochastic disturbances as TFP shocks. In light of this choice, we feel that it would be interesting to repeat the exercise of this Section using firm-level TFP growth instead of sales growth as the dependent variable in regression (1). In principle, this can be accomplished by obtaining a panel of firm-level Solow residuals from our dataset. Unfortunately, Compustat presents a series of shortcomings that make it quite far from ideal for this type of analysis. In spite of this caveat, in Appendix B we conduct this exercise. Its results are very similar to the ones presented here.

${ }^{8}$ We base this test on a regression similar to (2). The Breusch-Pagan test statistic is equal to 480.47, with a p-value lower than 0.0001 .

${ }^{9}$ This formulation results from the assumption of a particular functional form for the sectoral variance, $\sigma_{j}^{2}=\sigma^{2} \exp \left(\theta_{j}\right)$. The reader may realize that this is a special case of the multiplicative heteroscedasticity model analyzed by Harvey (1976).
} 


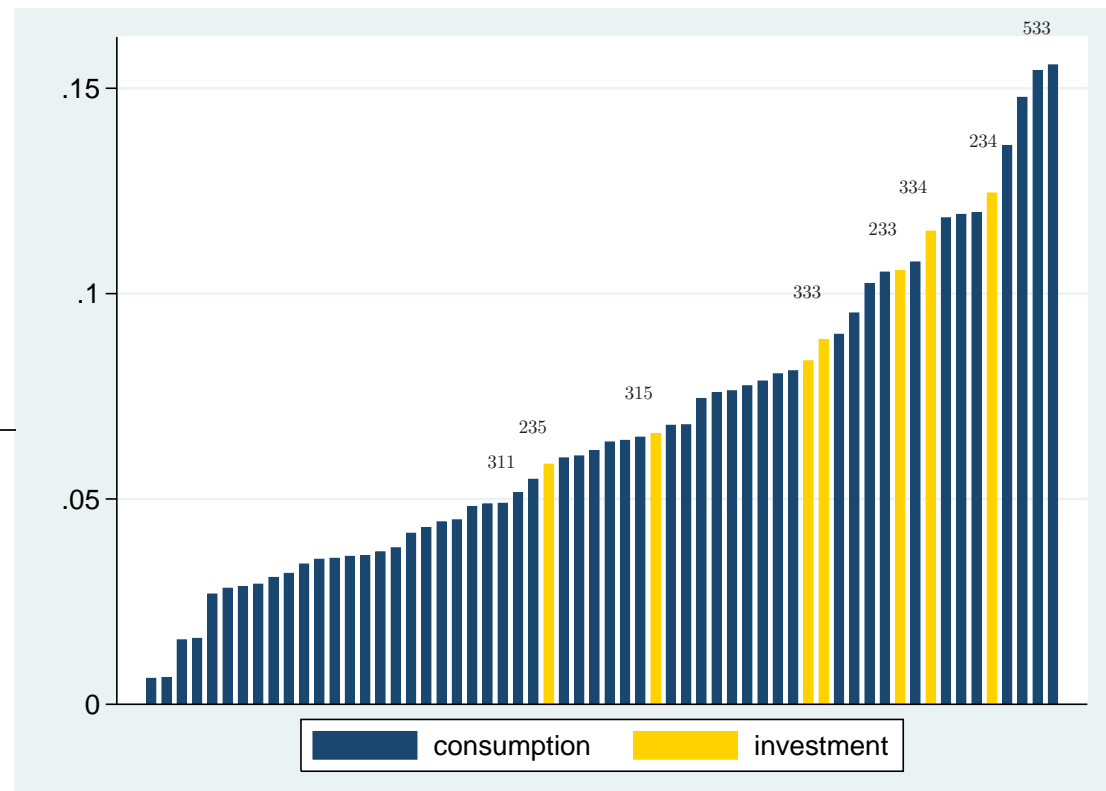

Figure 3: Volatility of sales growth per 3-digit industry.

estimate of the conditional standard deviation of sales growth for firms in sector $j$. The estimates for all sectors are reported in Table 4 and graphed in Figure 3, sorted in ascending order. Investment good sectors rank among the most volatile in the economy. This is the case for Machinery Manufacturing (NAICS code 333) and Computer and Electronic Product Manufacturing (334), as well as for Construction (233 and 234). Conversely, firms in Food Manufacturing (311) and Apparel Manufacturing (315), two of the largest industries in terms of value added in most economies, are the least volatile among the manufacturing sectors.

Interestingly, three of the four consumption good sectors that are at the top of the distribution are Owners and Lessors of Nonfinancial Assets (533), Oil and Gas Extraction (211), and Mining (212). The first includes firms primarily engaged in owning or leasing franchises, patents, and copyrights that they in turn license others to use. Many of these firms are research companies that develop innovations and then license them out to manufacturers. While our classification system qualifies these three sectors as consumption good producing, we are not accustomed to think of them as such. Their output consists exclusively of intermediate goods, the majority of which are purchased by sectors that sell to final consumers. In spite of this observation, consistency requires us to include them among consumption good sectors.

We have conducted a series of robustness checks, the details of which are reported in Appendix A. Our results do not change in any appreciable way when we vary the sample selection procedure or the regression equation specification. Therefore 
we interpret these findings as providing support for the claim that firms producing investment goods face a higher idiosyncratic risk than firms producing consumption goods.

In the remainder of this section we briefly address three questions: (i) Is selection likely to bias our estimates? (ii) Would data gathered in other countries confirm what we found in the case of the US? (iii) What causes the cross-sectoral variation in conditional sales growth volatility?

It is well known that Compustat is not a representative sample of the population of firms in the US, as it only includes companies whose stock is traded in an organized exchange. The question is whether this selection biases our results. Firms in Compustat tend to be larger and older than their peers not included in the sample, and therefore are less volatile. As noted above, we try to address this issue by controlling for age and size. However, there may be other, unknown factors, that cause firms' sales growth volatility to be systematically higher or lower than the average US firm's. As long as these factors have the same impact on consumption and investment good producing firms, the ranking of volatilities will not be influenced by the selection procedure. We will still be able to conclude that idiosyncratic risk is greater in investment-good producing sectors. As it will become clear in Section 3, this is what we need for most of our analysis to go through. The only results that depend on the magnitude of the volatility estimates are those obtained by the quantitative exercise conducted in Section 8. ${ }^{10}$

In developing our theory, we will maintain that the cross-sectoral heterogeneity in volatility that we documented for the United States applies to all other countries as well. Unfortunately, lack of detailed firm-level data for most countries prevents us from testing this claim. It is not clear, however, that even if firm-level data were available for low-investor protection countries, we would want to use it. According to Eaton and Kortum (2001), and consistently with our theory, relatively risky sectors do not arise at all in countries with weak institutions. ${ }^{11}$ This selection would undoubtedly bias downward the volatility estimates for such countries' investment good sectors.

\footnotetext{
${ }^{10}$ Davis, Haltiwanger, Jarmin, and Miranda (2006) have recently suggested that the bias introduced by Compustat is likely to be important for the characterization of certain phenomena, such as the evolution of firm-level volatility in the U.S. (see Comin and Philippon (2005)). However, for the reasons we just outlined, we conjecture that this is not the case for the phenomenon under consideration here. A verification of this conjecture is not possible for the time being, as alternative and comprehensive data sets, like the Longitudinal Business Database, are not readily available to the public.

${ }^{11}$ Most of the investment goods are classified as equipment. Eaton and Kortum (2001) show that the production of equipment as percentage of GDP varies greatly across countries. A cursory look at their data hints that the less equipment-intensive countries tend to have weaker institutions.
} 
Countries such as the US, where institutions are likely to be better, are relatively immune to this bias. For this reason, we believe that US data is the most appropriate evidence on which to base studies of investment good sectors' volatility. ${ }^{12}$

In the theoretical analysis that follows, differences in volatility across sectors are exogenous. We take this route because providing a rationalization for our empirical finding is not the purpose of this paper. We will assume that firms' technologies are subject to TFP-like shocks with sector-specific variances. While we have not experimented with alternative types of disturbances, we believe that the mechanism at the core of our model would have similar implications under different assumptions on the stochastic structure. Even though the results of our analysis do not depend on it, we believe that it would be of independent interest to understand what causes firms in one sector to face higher idiosyncratic risk than their peers in the other. Accounting for this heterogeneity may also provide insights into the determinants of the post-WWII increase in sales volatility recently documented by Comin and Philippon (2005). Our conjecture is that in the case of most investment and durable consumption goods there is a greater scope for process and product innovation. Klenow (1996)'s finding on the distribution of $\mathrm{R} \& \mathrm{D}$ expenditures across 2 - and 3-digit industries seem to be consistent with this hypothesis. ${ }^{13}$ Our idea is that in these industries firms are arranged on a quality ladder. The adoption of an innovation ahead of its peers allows a laggard to advance to the frontier, boosting its sales, possibly in a rather dramatic way. Conversely, the early adoption by a competitor has the potential to depress its results. Our argument is in the spirit of the quality ladder models of endogenous economic growth à la Grossman and Helpman (1991) and Aghion and Howitt (1992).

We now turn to the model.

\section{Model}

We consider a simple extension of the standard two-period, two-sector Overlapping Generations Model. The population is constant and the measure of each cohort is normalized to one. Individuals are risk-averse. Preferences are time-separable and the period utility, denoted by $u\left(c_{t}\right)$, displays constant relative risk aversion. ${ }^{14}$ Let $\sigma$ denote the coefficient of relative risk aversion. Agents discount second-period utility

\footnotetext{
${ }^{12}$ In Section 9 we argue that heterogeneity in volatility could explain international specialization patterns among investment goods.

${ }^{13}$ See Tables 2 and 3 of that paper, respectively.

${ }^{14}$ We restrict our attention to the CRRA family, because utility functions in this class display non-increasing absolute risk aversion and imply indirect utility functions that are log-separable in the interest rate.
} 
at the rate $\beta ; \beta>0$.

Young individuals are born without any endowment. In order to consume, they engage in the production of either consumption goods or investment goods. Both activities require capital, which is borrowed from the old via financial intermediaries. Old individuals are idle and consume from assets accumulated when young. The technologies in the two sectors are described by the production functions $y_{C t}=z_{C t} k_{C t}^{\alpha}$ and $y_{I t}=z_{I t} k_{I t}^{\alpha}$, respectively, with $\alpha \in(0,1)$. In either sector, capital depreciates at the constant rate $\delta \in(0,1)$. The two sectors only differ with respect to the distribution of the random variables $z_{C t}$ and $z_{I t}$. In order to capture the difference in volatility across sectors documented in Section 2, we assume that the standard deviation of $z_{I t}$ is always greater than the standard deviation of $z_{C t}$. For the sake of simplicity, here we posit that $z_{C t}=z_{C} \in \Re_{+}$for all $t$, while $z_{I t} \in\left\{z_{h}, z_{l}\right\} \in \Re_{+}^{2}$, with $z_{h}>z_{l}>0$, and $\operatorname{pr}\left\{z_{I t}=z_{h}\right\}=\rho, \rho \in(0,1)$. The hypothesis of no risk in the consumption good sector will be relaxed in Section 5 . The consumption good is the numeraire. We use $p_{t}$ to denote the price of the investment good and $N_{t}$ to denote the fraction of entrepreneurs (i.e. the fraction of young agents) engaged in the production of investment goods. Finally, we find it useful to define $\Delta \equiv z_{h}-z_{l}$.

We assume that the output realization is private information for the entrepreneurs. In the simple model considered here, this matters only for agents operating in the investment good sector. ${ }^{15}$ These entrepreneurs have the option of hiding some of their cash-flows from their financiers. Hiding, however, is costly. For every unit of cash-flow hidden, an entrepreneur ends up with only $\xi \in[0,1] .{ }^{16}$ The balance is lost in the hiding process. ${ }^{17}$ The parameter $\xi$ is our measure of the economy-wide level of investor protection. The larger is $\xi$, the lower the protection. The two extreme values identify the cases of complete absence of protection $(\xi=1)$ and perfect protection $(\xi=0)$. Finally, we assume that the intermediation industry is competitive and entry is free.

Figure 4 displays the sequence of events during the life of an investment-good producer. At the outset, he borrows capital, $k_{I t}$, from an intermediary, then invests and produces output equal to $z_{I t} f\left(k_{I t}\right)$. Next, he makes a claim about the outcome of his project $\hat{z}_{I t} \in\left\{z_{h}, z_{l}\right\}$, gives the intermediary output consistent with this claim,

\footnotetext{
${ }^{15}$ As already hinted at, this will not be the case in the generalization of this setup to be introduced in Section 5. There, entrepreneurs producing consumption goods will also face incentives to exploit their informational advantage.

${ }^{16}$ Our hiding cost resembles the falsification cost considered by Lacker and Weinberg (1989).

${ }^{17}$ All of our results follow even when a portion, or the totality of this balance accrues to the intermediaries. The only caveat is that in such case one needs to work with a continuum of outcomes. Otherwise, any hiding would be detected by the lender. See the Appendix to Castro, Clementi, and MacDonald (2004) for details.
} 
Borrows $k_{I t} \quad$ Obtains $z_{I t} f\left(k_{I t}\right) \quad$ Receives $\tau_{I t}\left(\hat{z}_{I t}\right) \quad$ Lends $s_{I t}$

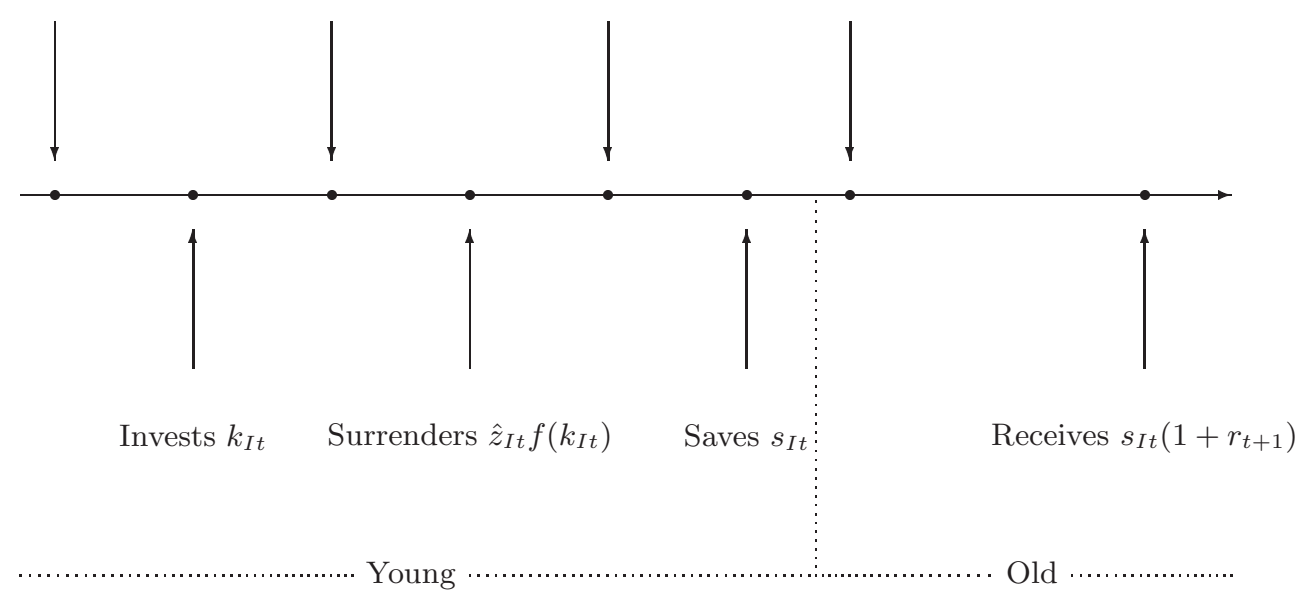

Figure 4: Timing.

i.e. $\hat{z}_{I t} f\left(k_{I t}\right)$, and receives a contingent transfer of consumption good $\tau_{I t}\left(\hat{z}_{I t}\right) .{ }^{18} \mathrm{~A}$ financing contract offered to a sector- $I$ entrepreneur consists of a capital advance, $k_{I t}$, and contingent transfers $\tau_{h t} \equiv \tau_{I t}\left(z_{h}\right)$ and $\tau_{l t} \equiv \tau_{I t}\left(z_{l}\right)$. At the end of the first period, investment good producers end up with income we denote by $m_{t}$. If the outcome is low, necessarily $m_{t}=\tau_{l t}$. Having no endowment, an agent is unable to misreport in the low state, since that would entail surrendering a level of output $z_{h} f\left(k_{I t}\right)$. If the outcome is high, truthful reporting yields $m_{t}=\tau_{h t}$, and concealing yields $m_{t}=\tau_{l t}+\xi p_{t} \Delta f\left(k_{I t}\right)$. By misreporting, an entrepreneur receives the transfer intended for low-outcome projects, $\tau_{l t}$, plus the fraction $\xi$ of the hidden output $p_{t} \Delta f\left(k_{I t}\right)$.

The life of entrepreneurs in the consumption good sector is characterized by the same sequence of events. The only difference is that, their outputs being a deterministic function of the inputs, their contracts collapse to a level of capital $k_{C t}$ and an uncontingent transfer $\tau_{C t}$. Their income is necessarily $m_{t}=\tau_{C t}$.

At the end of the first stage of their lives, all agents, regardless of their occupations, consume part of their incomes and save the rest. At the beginning of the second stage, they lend their savings to intermediaries at the market rate. Intermediaries channel those funds to the new cohort of young people. At the end of their lives, agents receive and consume principal plus interest. Notice that the rate $r_{t}$ denotes the return in consumption goods to the investment of one unit of consumption good.

\footnotetext{
${ }^{18}$ In the appendix to Castro, Clementi, and MacDonald (2004) we show that under our assumptions the Constrained-Pareto optimal contract always requires the output surrendered to be consistent with the report. In turn, this implies no hiding along the equilibrium path.
} 


\section{Competitive equilibrium}

We start by considering an entrepreneur's consumption-saving decision. This simple problem is the same for all agents. Let $v\left(m_{t}, r_{t+1}\right)$ denote the indirect utility of an agent born at time $t$, conditional on having received an income $m_{t}$ and on facing an interest rate $r_{t+1}$. Then,

$$
v\left(m_{t}, r_{t+1}\right) \equiv u\left[m_{t}-s\left(m_{t}, r_{t+1}\right)\right]+\beta u\left[\left(1+r_{t+1}\right) s\left(m_{t}, r_{t+1}\right)\right]
$$

where the optimal saving function $s\left(m_{t}, r_{t+1}\right)$ is

$$
s\left(m_{t}, r_{t+1}\right) \equiv \arg \max _{s}\left\{u\left(m_{t}-s\right)+\beta u\left[\left(1+r_{t+1}\right) s\right]\right\}
$$

Under our assumptions on preferences, it follows that

$$
s\left(m_{t}, r_{t+1}\right)=\kappa\left(r_{t+1}\right) m_{t}
$$

and

$$
v\left(m_{t}, r_{t+1}\right)=u\left(m_{t}\right)\left[u\left(1-\kappa\left(r_{t+1}\right)\right)+\beta u\left(\kappa\left(r_{t+1}\right)\left(1+r_{t+1}\right)\right)\right],
$$

where

$$
\kappa\left(r_{t+1}\right)=\frac{1}{1+\beta^{-\frac{1}{\sigma}}\left(1+r_{t+1}\right)^{\frac{\sigma-1}{\sigma}}} .
$$

We now characterize the financing contracts offered to entrepreneurs. Those who opt for the consumption good sector will implement the efficient scale. Their income $\tau_{C t}$ is the value of the following problem:

$$
\max _{k_{C t}} z_{C} k_{C t}^{\alpha}-\left(r_{t}+\delta\right) p_{t} k_{C t} .
$$

Entrepreneurs in the investment good sector will be offered contracts $\left(k_{I t}, \tau_{h t}, \tau_{l t}\right)$ that solve

$$
\max _{k_{I t}, \tau_{h t}, \tau_{l t}} \rho v\left(\tau_{h t}, r_{t+1}\right)+(1-\rho) v\left(\tau_{l t}, r_{t+1}\right),
$$

subject to incentive compatibility for entrepreneurs whose projects are of high quality, i.e.,

$$
v\left(\tau_{h t}, r_{t+1}\right) \geq v\left[\tau_{l t}+\xi p_{t} \Delta k_{I t}^{\alpha}, r_{t+1}\right],
$$

and the zero-profit condition for intermediaries:

$$
\bar{\tau}_{t} \equiv \rho \tau_{h t}+(1-\rho) \tau_{l t}=p_{t} \bar{z}_{I} k_{I t}^{\alpha}-\left(r_{t}+\delta\right) p_{t} k_{I t},
$$

with $\bar{z}_{I}=\rho z_{h}+(1-\rho) z_{l}$. We now define a competitive equilibrium. 
Definition 1 Given an initial aggregate capital stock $K_{0}>0$, a competitive equilibrium is a non-negative consumption level of the initial old $c_{0}^{o}$, contingent non-negative consumption allocations for young and old individuals in the investment good sector, $\left\{c_{h t}^{y}, c_{l t}^{y}\right\}_{t=0}^{\infty}$ and $\left\{c_{h t}^{o}, c_{l t}^{o}\right\}_{t=1}^{\infty}$, non-negative consumption allocations for young and old individuals in the consumption good sector $\left\{c_{C t}^{y}\right\}_{t=0}^{\infty}$ and $\left\{c_{C t}^{o}\right\}_{t=1}^{\infty}$, sequences of contracts $\left\{k_{I t}, \tau_{h t}, \tau_{l t}\right\}_{t=0}^{\infty}$ and $\left\{k_{C t}, \tau_{C t}\right\}_{t=0}^{\infty}$, measures of entrepreneurs in the investment good sectors $\left\{N_{t}\right\}_{t=0}^{\infty}$, relative prices $\left\{p_{t}\right\}_{t=0}^{\infty}$, and interest rates $\left\{r_{t}\right\}_{t=0}^{\infty}$, such that

1. $c_{0}^{o}=p_{0} K_{0}\left(1+r_{0}\right)$ and at all $t \geq 0$.

2. $c_{i t}^{y}=\tau_{i t}-s\left(\tau_{i t}, r_{t+1}\right)$ and $c_{i t+1}^{o}=s\left(\tau_{i t}, r_{t+1}\right)\left(1+r_{t+1}\right)$, for $i=h, l$;

3. $c_{C t}^{y}=\tau_{C t}-s\left(\tau_{C t}, r_{t+1}\right)$ and $c_{C t}^{o}=s\left(\tau_{C t}, r_{t+1}\right)\left(1+r_{t+1}\right)$;

4. $\left\{k_{C t}, \tau_{C t}\right\}$ solves problem (P1);

5. $\left\{k_{I t}, \tau_{h t}, \tau_{l t}\right\}$ solves problem (P2);

6. $N_{t} \in[0,1]$

7. young individuals are indifferent between the two sectors:

$$
v\left(\tau_{C t}, r_{t+1}\right)=\rho v\left(\tau_{h t}, r_{t+1}\right)+(1-\rho) v\left(\tau_{l t}, r_{t+1}\right) ;
$$

8. aggregate savings are equal to the value of the capital stock:

$$
p_{t} K_{t+1}=N_{t}\left[\rho s\left(\tau_{h t}, r_{t+1}\right)+(1-\rho) s\left(\tau_{l t}, r_{t+1}\right)\right]+\left(1-N_{t}\right) s\left(\tau_{C t}, r_{t+1}\right)
$$

9. gross investment equals the production of investment goods:

$$
K_{t+1}=(1-\delta) K_{t}+N_{t} \bar{z}_{I} k_{I t}^{\alpha}
$$

10. the market for capital clears:

$$
K_{t}=N_{t} k_{I t}+\left(1-N_{t}\right) k_{C t}
$$




\subsection{Benchmark: Perfect investor protection $(\xi=0)$}

In this section we show that, for $\xi=0$, our model reduces to the standard two-period, two-sector model of capital accumulation. The necessary condition for problem (P1) is

$$
\alpha z_{C} k_{C t}^{\alpha-1}=\left(r_{t}+\delta\right) p_{t}
$$

In turn, this implies that

$$
\tau_{C t}=(1-\alpha) z_{C} k_{C t}^{\alpha} .
$$

It is easy to see that for $\xi=0$, the optimal contract in the investment good sector implements the first-best allocation. Such allocation must satisfy

$$
\alpha \bar{z}_{I} k_{I t}^{\alpha-1}=\left(r_{t}+\delta\right)
$$

and

$$
\tau_{I t} \equiv \tau_{h t}=\tau_{l t}=p_{t}(1-\alpha) \bar{z}_{I} k_{I t}^{\alpha} .
$$

Conditions (11) and (13) imply that the relative price of the investment good satisfies

$$
p_{t}=\frac{z_{C}}{\bar{z}_{I}}\left(\frac{k_{C t}}{k_{I t}}\right)^{\alpha-1} .
$$

Using (4), (12), and (14), we can rewrite the occupational choice condition (7) as

$$
u\left[(1-\alpha) z_{C} k_{C t}^{\alpha}\right]=u\left[p_{t}(1-\alpha) \bar{z}_{I} k_{I t}^{\alpha}\right]
$$

Since $u$ is strictly increasing, conditions (15) and (16) imply that $k_{C t}=k_{I t}$. This, along with condition (10), implies that $k_{C t}=k_{I t}=K_{t}$, so that $p_{t}=z_{C} / \bar{z}_{I}$ and $\tau_{t} \equiv \tau_{C t}=\tau_{I t}$. Finally, by (3), condition (8) leads us to conclude that

$$
K_{t+1}=(1-\alpha) \kappa\left(r_{t+1}\right) \bar{z}_{I} K_{t}^{\alpha}
$$

Aggregation holds: the latter condition, along with (13), can be used to recover the equilibrium sequences for $K_{t}$ and $r_{t}$. Then, the sequence for $N_{t}$ can be computed using condition (9). We close this section noting that for $z_{C}=\bar{z}_{I}$ the model's implications are identical to those of the standard one-sector model.

\subsection{Imperfect investor protection $(\xi \in(0,1])$}

First, notice that our assumptions on preferences imply that Problem (P2) is independent from $r_{t+1}$. Using condition (4), one can easily show that (P2) reduces to the 
following program:

$$
\begin{gathered}
\max _{k_{I t}, \tau_{h t}, \tau_{l t}} \rho u\left(\tau_{h t}\right)+(1-\rho) u\left(\tau_{l t}\right), \\
\text { subject to } u\left(\tau_{h t}\right) \geq u\left(\tau_{l t}+\xi p_{t} \Delta k_{I t}^{\alpha}\right), \\
\bar{\tau}_{I t} \equiv \rho \tau_{h t}+(1-\rho) \tau_{l t}=p_{t}\left[\bar{z}_{I} k_{I t}^{\alpha}-\left(r_{t}+\delta\right) k_{I t}\right] .
\end{gathered}
$$

Strict concavity of the utility function implies that constraint (17) binds. Then, by strong monotonicity of $u(\cdot)$, it follows that

$$
\tau_{h t}=\tau_{l t}+\xi p_{t} \Delta k_{I t}^{\alpha}
$$

The term $\tau_{h t}-\tau_{l t}=\xi p_{t} \Delta k_{I t}^{\alpha}$ is a measure of the income risk borne by entrepreneurs in the investment good sector. It depends positively on the scale of production and negatively on the level of investor protection. By (18), the contracting problem simplifies to

$$
\begin{aligned}
& \max _{k_{I t}, \bar{\tau}_{t}} \rho u\left[\bar{\tau}_{t}+(1-\rho) \xi p_{t} \Delta k_{I t}^{\alpha}\right]+(1-\rho) u\left[\bar{\tau}_{t}-\rho \xi p_{t} \Delta k_{I t}^{\alpha}\right] \\
& \text { subject to } \bar{\tau}_{t}=p_{t}\left[\bar{z}_{I} k_{I t}^{\alpha}-\left(r_{t}+\delta\right) k_{I t}\right] .
\end{aligned}
$$

The necessary and sufficient condition for maximization is

$$
r_{t}+\delta=\alpha k_{I t}^{\alpha-1}\left[\bar{z}_{I}+\rho(1-\rho) \xi \Delta \omega_{t}\right]
$$

where

$$
\omega_{t} \equiv \frac{u^{\prime}\left(\tau_{h t}\right)-u^{\prime}\left(\tau_{l t}\right)}{\rho u^{\prime}\left(\tau_{h t}\right)+(1-\rho) u^{\prime}\left(\tau_{l t}\right)} .
$$

The term $\rho(1-\rho) \xi \Delta \omega_{t}<0$ is the wedge between the private and social marginal product of capital in the investment good sector, which is induced by imperfect risksharing. To shed some light on its meaning, we rewrite it as

$$
\rho(1-\rho) \xi \Delta \omega_{t}=\xi \frac{\rho u^{\prime}\left(\tau_{h t}\right)\left(z_{h}-\bar{z}_{I}\right)+(1-\rho) u^{\prime}\left(\tau_{l t}\right)\left(z_{l}-\bar{z}_{I}\right)}{\rho u^{\prime}\left(\tau_{h t}\right)+(1-\rho) u^{\prime}\left(\tau_{l t}\right)} .
$$

In turn, this allows to rewrite condition (19) as

$$
\begin{aligned}
{\left[\alpha \bar{z}_{I t} k_{I t}^{\alpha-1}-\left(r_{t}+\delta\right)\right] } & {\left[\rho u^{\prime}\left(\tau_{h t}\right)+(1-\rho) u^{\prime}\left(\tau_{l t}\right)\right]=} \\
& -\alpha k_{I t}^{\alpha-1}\left[\rho u^{\prime}\left(\tau_{h t}\right)\left(z_{h}-\bar{z}_{I}\right)+(1-\rho) u^{\prime}\left(\tau_{l t}\right)\left(z_{l}-\bar{z}_{I}\right)\right]
\end{aligned}
$$

The term on the left-hand side is the marginal benefit of increasing capital. Raising $k_{I t}$ affects the resources available for distribution to the entrepreneur in all states of nature. The term on the right-hand side is the marginal cost of increasing capital. This becomes evident once one realizes that $\tau_{j t}=\bar{\tau}_{t}+\xi p_{t}\left[z_{j}-\bar{z}\right] k_{I t}^{\alpha}$ for $j=h, l$. 
Incentive compatibility implies that a larger capital can be accommodated only at the cost of a higher variance in entrepreneurial income.

Proposition 1 shows that under our assumptions on preferences, the transfers are linear in the output level and the wedge is scale-invariant.

Proposition 1 For all $t \geq 0, \tau_{h t}=p_{t} g_{h} k_{I t}^{\alpha}$ and $\tau_{l t}=p_{t} g_{l} k_{I t}^{\alpha}$ for some positive constants $g_{h}$ and $g_{l}$. Furthermore, $\omega_{t}=\omega=\frac{g_{h}^{-\sigma}-g_{l}^{-\sigma}}{\rho g_{h}^{-\sigma}+(1-\rho) g_{l}^{-\sigma}}$.

Proof. We use conditions (17) and (18) to express $\tau_{h t}$ and $\tau_{l t}$ as functions of $k_{I t}$ :

$$
\tau_{j t}=p_{t}\left[\left(\bar{z}_{I}(1-\xi)+\xi z_{j}\right) k_{I t}^{\alpha}-\left(r_{t}+\delta\right) k_{I t}\right], j=h, l
$$

By (19), we can rewrite the latter expression as

$$
\tau_{j t}=p_{t} k_{I t}^{\alpha}\left[(1-\alpha-\xi) \bar{z}_{I}-\alpha \rho(1-\rho) \xi \Delta \omega_{t}+\xi z_{j}\right], j=h, l .
$$

We now conjecture that $\tau_{h t}=p_{t} g_{h} k_{I t}^{\alpha}$ and $\tau_{l t}=p_{t} g_{l} k_{I t}^{\alpha}$. For our conjecture to be verified, the constants $g_{h}$ and $g_{l}$ must solve the following system:

$$
\begin{aligned}
g_{h} & =(1-\alpha-\xi) \bar{z}_{I}-\alpha \rho(1-\rho) \xi \Delta \omega_{t}+\xi z_{h} \\
g_{l} & =(1-\alpha-\xi) \bar{z}_{I}-\alpha \rho(1-\rho) \xi \Delta \omega_{t}+\xi z_{l} \\
\omega & =\frac{g_{h}^{-\sigma}-g_{l}^{-\sigma}}{\rho g_{h}^{-\sigma}+(1-\rho) g_{l}^{-\sigma}}
\end{aligned}
$$

It is straightforward to check that there always exist strictly positive constants $g_{h}$ and $g_{l}$ that solve (20)-(22). Since the solution to (P3) is unique, the result holds.

As a consistency check, one can verify that for $\xi=0$ condition (19) reduces to $r_{t}+\delta=\alpha \bar{z}_{I} k_{I t}^{\alpha-1}$ and that $g_{h}=g_{l}=(1-\alpha) \bar{z}_{I}$. We are back to the case analyzed in Section 4.1.

Proposition 2 establishes that the size of the wedge between private and social marginal product of capital is larger, the poorer the quality of institutions. Intuition for this result can be gained by inspecting condition (18). It reveals that in this framework adding one unit of capital increases uninsured idiosyncratic risk at a rate that is strictly increasing in $\xi$. Therefore for given interest rate the privately optimal firm scale will be decreasing in $\xi$, and for given scale the average transfer $\bar{\tau}_{t}$ will be increasing in $\xi$.

Proposition 2 The term $\omega=\frac{g_{h}^{-\sigma}-g_{l}^{-\sigma}}{\rho g_{h}^{-\sigma}+(1-\rho) g_{l}^{-\sigma}}$ is strictly decreasing in $\xi{ }^{19}$

\footnotetext{
${ }^{19}$ Proofs not reported in the main body of the paper can be found in Appendix C.
} 
Let's now turn our attention to the relative price $p_{t}$. Let $Q_{t} \equiv k_{C t} / k_{I t}$. By Proposition 1, conditions (11) and (19) allow us to express the relative price of the investment good as

$$
p_{t}=\frac{z_{C}}{\bar{z}_{I}+\rho(1-\rho) \xi \Delta \omega} Q_{t}^{\alpha-1} .
$$

Proposition 1 also allows us to rewrite the occupational choice condition (7) as

$$
u\left[(1-\alpha) z_{C} k_{C t}^{\alpha}\right]=\rho u\left(p_{t} g_{h} k_{I t}^{\alpha}\right)+(1-\rho) u\left(p_{t} g_{l} k_{I t}^{\alpha}\right) .
$$

Solving the latter for $p_{t}$ yields

$$
p_{t}=\frac{(1-\alpha) z_{C}}{\left[\rho g_{h}^{1-\sigma}+(1-\rho) g_{l}^{1-\sigma}\right]^{1 /(1-\sigma)}} Q_{t}^{\alpha} .
$$

One can easily solve (23) and (24) for $p_{t}$ and $Q_{t}$. Interestingly, both variables turn out to be time-invariant.

Corollary 1 For all $t \geq 0, p_{t}=p$ and $Q_{t}=Q$.

This finding allows us to characterize the relation between $p$ and $\xi$ without having to compute the whole competitive equilibrium allocation. Proposition 3 establishes that the relative price of capital is higher, the poorer the investor protection.

Proposition 3 The relative price of capital $p$ is strictly increasing in $\xi$.

Figure 5 gives a qualitative rendering of the comparative statics of $p$ and $Q$ with respect to $\xi$. The exercise characterizes the effects of worsening investor protection (increasing $\xi$ from $\xi_{0}$ to $\xi_{1}$ ). The schedules labeled $F O C$ and $I N D$ depict the relations between $p$ and $Q$ implied by equations (23) and (24), respectively. Solid lines refer to the case of high investor protection $\left(\xi_{0}\right)$. Dotted lines instead refer to the case of low protection $\left(\xi_{1}\right)$.

The $I N D$ schedule is upward sloping because as $Q=k_{C t} / k_{I t}$ increases, an increase in the relative price is needed to keep agents indifferent between the two occupations. Also, recall that poorer investor protection means less risk-sharing. This is reflected in the relation $g_{h}=g_{l}+\xi \Delta$. This implies that the compensating increase in the price must be larger, the poorer the investor protection. As a consequence, IND becomes steeper as $\xi$ increases. Let's now turn to the FOC schedule. It is simply the locus of the $(p, Q)$ pairs consistent with the equality of the marginal products, expressed in capital goods. These are $\alpha k_{I t}^{\alpha-1}\left[\bar{z}_{I}+\rho(1-\rho) \xi \Delta \omega\right]$ and $\alpha \bar{z}_{C} k_{C t}^{\alpha-1} / p$. To maintain such equality as $p$ increases, $k_{C}$ must decrease with respect to $k_{I}$. As investor protection deteriorates, such decrease becomes smaller, since higher $\xi$ implies a larger wedge $|\rho(1-\rho) \xi \Delta \omega|$. This is why $F O C_{1}$ lies above $F O C_{0}$. 


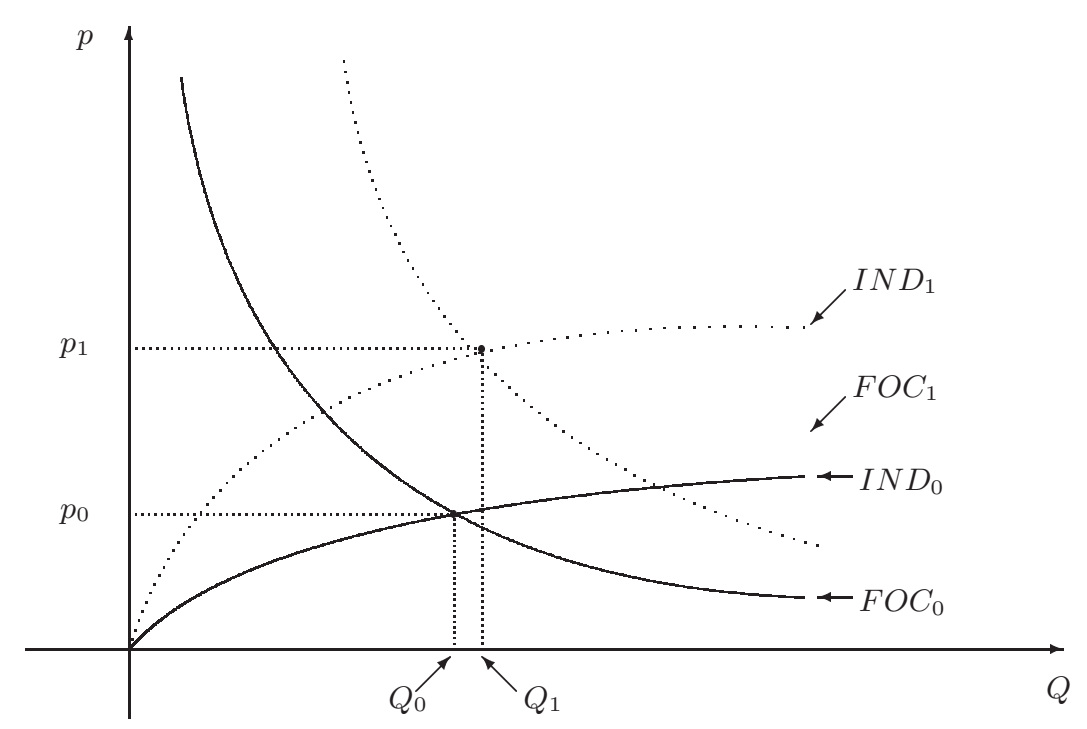

Figure 5: Comparative statics with respect to $\xi$.

The bottom line is that both curves shift upwards as $\xi$ increases. As a result, the relative price necessarily increases.

It turns out that $Q$ is also monotone increasing in $\xi .{ }^{20}$ Should this be a robust implication of our assumptions, it would provide a testable restriction. However, this particular result is not general. When we allow for a continuum of states and for risk in the consumption sector (see Section 5) or for ex-ante heterogeneity (see Appendix $\mathrm{D}), Q$ is monotone increasing in $\xi$ only on a subset of the parameter space.

We now turn to the full characterization of the equilibrium. Notice that condition (10) implies that $k_{I t}=\frac{K_{t}}{N_{t}+\left(1-N_{t}\right) Q}$. We can substitute this expression into equations (8), (9), and (11), to obtain

$$
\begin{aligned}
p K_{t+1} & =\kappa\left(r_{t+1}\right)\left[\frac{K_{t}}{N_{t}+\left(1-N_{t}\right) Q}\right]^{\alpha}\left[p N_{t}\left(\rho g_{h}+(1-\rho) g_{l}\right)+\left(1-N_{t}\right)(1-\alpha) z_{C} Q^{\alpha}\right] \\
K_{t+1} & =(1-\delta) K_{t}+N_{t} \bar{z}_{I}\left(\frac{K_{t}}{N_{t}+\left(1-N_{t}\right) Q}\right)^{\alpha} \\
p\left(r_{t}+\delta\right) & =\alpha z_{C}\left(\frac{Q K_{t}}{N_{t}+\left(1-N_{t}\right) Q}\right)^{\alpha-1}
\end{aligned}
$$

Once computed $p$ and $Q$, and given $K_{0}$, the three conditions above are sufficient to characterize the equilibrium paths for $K_{t}, N_{t}$, and $r_{t} \cdot{ }^{21}$ The sequence of consumption

\footnotetext{
${ }^{20}$ See Appendix $\mathrm{C}$ for a proof of this claim.

${ }^{21}$ Solving equation (27) for $r_{t+1}$ and substituting it into (25) yields a bi-dimensional dynamical system in $K_{t}$ and $N_{t}$. This implies that, in general, the initial condition $K_{0}$ is not enough to
} 
allocations and the other quantities of interest can be easily recovered using the relations outlined earlier in this section.

Recall that our ultimate objective is to evaluate whether our theory can account for the development facts described in the Introduction. To this end, in the next section we introduce and parameterize a more general version of our model. In Sections 6 and 7 we use it to conduct a comparative steady-state analysis with respect to the parameter $\xi$. Finally, in Section 8 we conduct a quantitative exercise: we ask whether the model is able to generate as much cross-country dispersion in relative prices and investment rates as in the 1996 Penn World Tables.

\section{Calibration}

We amend the setup introduced in Section 3 along three dimensions: (i) we allow for risk in the consumption good sector, (ii) productivity shocks are now continuously distributed, and (iii) we introduce exogenous productivity growth. These changes yield a model which is better suited for quantitative analysis. Production in sector $j, j=I, C$, is still given by $y_{j t}=z_{j t} k_{j t}^{\alpha}$. The random variable $z_{j t}$, however, is now continuously distributed on the set $\left(\gamma^{t} z_{\text {min }},+\infty\right), z_{\text {min }}>0 .{ }^{22}$ We assume that $\log \left(z_{j t}-\gamma^{t} z_{\text {min }}\right) \sim N\left(\mu_{j}, \eta_{j}^{2}\right)$. In the engineering literature, $\gamma^{t} z_{\min }$ is sometimes known as shift or location parameter. Heuristically, the distribution of $z_{j t}$ shifts to the right at the rate $\gamma \cdot{ }^{23}$

In picking our parameter values, we consider a world economy consisting of a unit measure of countries, each of which drew its value of $\xi$ from the set $[0,1]$, according to the uniform probability distribution. This way, our model induces a distribution in the space of relative price and balanced-growth investment rate. Countries live in autarky. International trade and capital flows will be allowed for in Sections 7 and 8.

The parameter values are listed in Table 1 . Individuals are assumed to have a productive life of 60 years. This implies a 30-year model period. The parameter $\sigma$ is set to 1.5 , a standard value in quantitative analysis and consistent with the empirical evidence. The discount factor $\beta$ is such that the annual real interest rate in the United States, the country we associate with perfect investor protection $(\xi=0)$,

determine a solution. In our case, however, it is. This is because, as it turns out, a competitive equilibrium must be a saddle point path. When initialized with pairs $\left(K_{0}, N_{0}\right)$ not on the saddlepoint path, the system generates sequences that violate one or more equilibrium conditions in finite time. We are not able to prove that the saddle-path solution is unique, but numerical results hint that this is the case. Thus, for given $K_{0}, N_{0}$ is pinned down by the requirement that the pair be on the saddle path.

${ }^{22}$ The lower bound $z_{\text {min }}$ is introduced for technical reasons that are discussed in Appendix E.

${ }^{23}$ The equilibrium allocation of this more general model is entirely analogous to that described in Section 4. For this reason, we confine it to Appendix E. 
equals $6.5 \%$. The parameter $\alpha$ is set to $1 / 3$, the value considered by other studies of entrepreneurial behavior such as Burstein and Monge-Naranjo (2005) and Buera (2003). ${ }^{24}$ We compute the world average annual growth rate of real GDP per worker to be about $2.3 \%$ in the Penn World Tables, equivalent to a 30-year growth rate of output of $97.8 \%$. This observation implies that $\gamma=1.978^{1-\alpha}$. We set the annual depreciation rate to $8 \%$, to ensure an investment rate in the US of $20 \%$, about the same as in the data. The world's relative price of investment goods, $p^{w}$, is obtained as the cross-country average of the relative prices produced by the model.

The remaining four parameters are those characterizing the distributions of $z$ in the two sectors. Calibrating them is obviously a key element of our analysis. Since there are no scale effects in our model, we can normalize one of the means. We decide to set $\mu_{C}$ so that $\bar{z}_{C}=1$. We select $\eta_{C}$ and $\eta_{I}$ so that the standard deviations of the sales growth rates in the consumption and in the investment good sectors are 0.049 and 0.12 , respectively. These are our estimates of sales growth rate volatility in the Food Manufacturing and in the Computer and Electronic Product Manufacturing sector, respectively (see Table 4 in Appendix A). ${ }^{25}$ We would also like to set $\mu_{I}$ in order to match the average sales growth rate in the investment good sector (or its ratio to the average growth in the consumption good sector). Unfortunately, in our simple model there is no mapping between $\mu_{I}$ and that moment of the sales growth distribution. By construction, average sales growth rates are identically zero in our setup, in both sectors. Therefore, we set $\mu_{I}$ so that the model-implied cross-country variation in the relative price of investment goods (with respect to the US) matches its observed value. Given the high nonlinearity of our model and the restrictions imposed by the remaining parameters, it is not guaranteed that such a $\mu_{I}$ exists. As it turns out, however, our model can indeed generate the observed dispersion in relative prices.

\footnotetext{
${ }^{24}$ Atkeson and Kehoe (2005) find that the share of income accruing to capital in the US is only 0.2 . We are hesitant in adopting their value, because in our model the only two factors of production are physical capital and entrepreneurial ability. It turns out, however, that the model's implications do not change in any appreciable way when we re-calibrate it with $\alpha=0.2$. In particular, the qualitative patterns illustrated by Figure 6 are unchanged. The quantitative exercise in Section 8 below was also performed for both values of $\alpha$, yielding very similar results.

${ }^{25}$ Strictly speaking, our model does not produce implications for firms' sales growth rate. This is because firms operate for one model's period only. We define the time- $t$ economy-wide detrended average growth rate in sector $j$ as $\int_{Z} \int_{Z} \log \left(\frac{z^{\prime} \hat{k}_{j, t+1}^{\alpha}}{z \hat{k}_{j t}^{\alpha}}\right) f_{j}(z) f_{j}\left(z^{\prime}\right) d z d z^{\prime}$, where $Z=\left(z_{\min },+\infty\right)$ and $f_{j}(z)$ is the density of the lognormal distribution with shift parameter $z_{\min }$. In balanced-growth steady state, such statistic is always zero by construction. Therefore the model's standard deviation of the sales growth rate boils down to the square root of $\int_{Z} \int_{Z}\left[\log \left(\frac{z^{\prime}}{z}\right)\right]^{2} f_{j}(z) f_{j}\left(z^{\prime}\right) d z d z^{\prime}$. Our definition of growth rate can be rationalized by assuming that the technologies are infinitely lived and are passed down from generation to generation.
} 


\begin{tabular}{cccccccccc}
\hline$\beta$ & $\sigma$ & $\alpha$ & $\delta$ & $\gamma$ & $\mu_{C}$ & $\eta_{C}$ & $\mu_{I}$ & $\eta_{I}$ & $z_{\min }$ \\
\hline 0.194 & 1.5 & $1 / 3$ & 0.918 & 1.576 & -0.405 & 0.051 & -21.654 & 6.677 & 0.332 \\
\hline
\end{tabular}

Table 1: Parameter Values

\section{Comparative Statics}

Our theory predicts that the quality of legal institutions should be negatively correlated with the relative price of capital goods. The purpose of this section is to develop implications for the co-variation between the quality of legal institutions and other variables of interest for development economics, among which GDP and the investment rate, measured both in domestic and international prices. To this effect, we characterize the steady-state relationship between the parameter $\xi$ and those variables. Figure 6 depicts the steady-state values implied by all $\xi \in[0,1]$. The remaining parameter values are those listed in Table 1. Unless otherwise noted, the figures are expressed relative to the outcome under perfect investor protection $(\xi=0)$.

Consistently with Proposition 3, the relative price of capital is higher, the poorer the investor protection. We have already argued that this happens because under our assumption on the cross-sectoral variation in baseline idiosyncratic risk, poor investor protection introduces a distortion in the allocation of resources between the investment good and the consumption good sector. Such distortion is also responsible for the lower levels of capital stock and GDP.

Now consider the first two panels on the bottom row. They depict the steadystate values of the investment rate measured using domestic and international prices, respectively. In the first case, the relevant price is the equilibrium value implied by $\xi$ (which is plotted in the third panel on the first row). The investment rate is simply $I / Y=p N \bar{z}_{I} k_{I}^{\alpha} /\left[p N \bar{z}_{I} k_{I}^{\alpha}+(1-N) \bar{z}_{C} k_{C}^{\alpha}\right]$. This quantity does not vary substantially with investor protection, because the relative price adjusts for the change in investor protection. In the second case, the relevant price is the average relative price (i.e. the mean of the prices in the third panel on the first row, with respect to the uniform distribution). The investment rate is $I^{p p p} / Y^{p p p}=p^{w} N \bar{z}_{I} k_{I}^{\alpha} /\left[p^{w} N \bar{z}_{I} k_{I}^{\alpha}+\right.$ $\left.(1-N) \bar{z}_{C} k_{C}^{\alpha}\right]$. Notice that the comparative statics of this quantity does not depend on the particular value assumed by $p^{w}$. What matters is $p^{w}$ 's invariance to the quality of institutions.

Figure 6 also shows that measured TFP declines with $\xi$. Consistently with the 

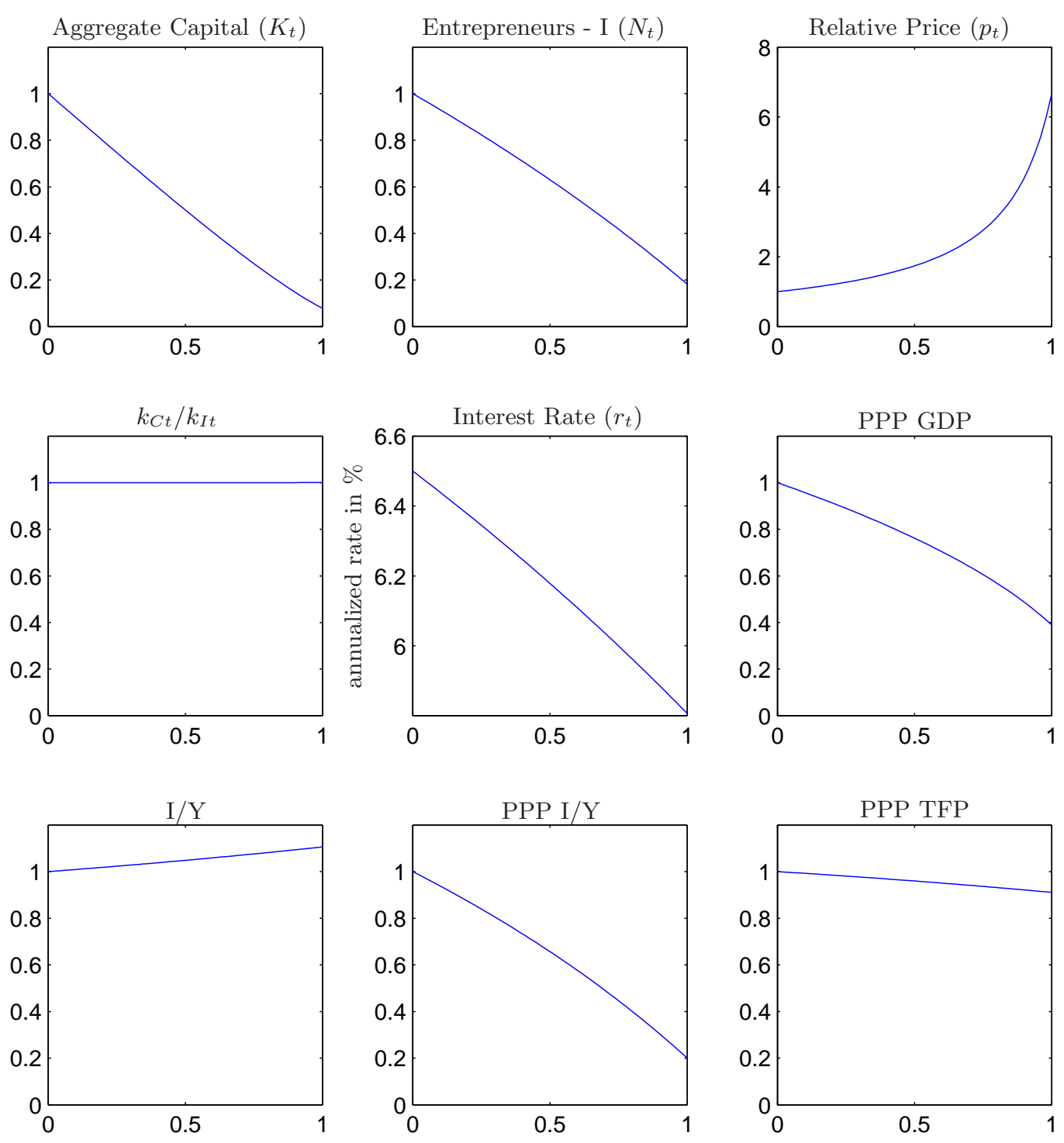

Figure 6: Steady-State Values for $\xi \in[0,1]$.

empirical literature, ${ }^{26}$ the Solow residual is computed as $Z=Y^{P P P} K^{-\alpha}$, where $Y^{P P P}=p^{w} N \bar{z}_{I} k_{I}^{\alpha}+(1-N) \bar{z}_{C} k_{C}^{\alpha}$. This yields:

$$
\begin{aligned}
Z & =\bar{z}_{C}\left[\frac{p^{w} \bar{z}_{I}}{\bar{z}_{C}} N\left(\frac{k_{I}}{K}\right)^{\alpha}+(1-N)\left(\frac{k_{C}}{K}\right)^{\alpha}\right] \\
& =\bar{z}_{C}\left[\frac{p^{w} \bar{z}_{I}}{\bar{z}_{C}} N\left(\frac{1}{N+(1-N) Q}\right)^{\alpha}+(1-N)\left(\frac{Q}{N+(1-N) Q}\right)^{\alpha}\right] .
\end{aligned}
$$

The above expressions help understanding why measured TFP varies across countries even in the absence of any heterogeneity in technology. As long as countries differ in investor protection, they will be characterized by different allocations of factors

\footnotetext{
${ }^{26}$ See for example Hall and Jones (1999) and Klenow and Rodriguez-Clare (1997).
} 
(capital and entrepreneurs) across sectors. That is, in general $Q$ and $N$ will vary with $\xi$. In the case of our parameterization, $\mathrm{Q}$ is basically invariant; the scale of production is about the same across sectors, and so is the productivity of capital. Measured TFP drops because the fraction of entrepreneurs active in the investment good sector decreases with $\xi$. Obviously this argument is correct if and only if $p^{w}>z_{C} / \bar{z}_{I}$. This condition is always satisfied, since $\bar{z}_{C} / \bar{z}_{I}$, the domestic price for a country with perfect investor protection, also constitutes the lower bound for the world price. Because of imperfect investor protection, the international price of investment goods is higher than the social marginal rate of transformation. Therefore any factor reallocation away from the investment sector reduces measured TFP. ${ }^{27}$ In conclusion, cross-country differences in legal institutions are able to generates differences not only in accumulation rates, but also in measured aggregate total factor productivity.

We now find it useful to relate our findings to the literature. Chari, Kehoe, and McGrattan (1996) and Restuccia and Urrutia (2001) have argued that inefficiencies specific to the investment-good producing sector can account for the evidence on relative prices and investment rates. These inefficiencies, or wedges, may be the result of explicit taxation, tariffs, regulation, corruption, or other economic rents. ${ }^{28}$ The purpose of those papers is not to understand which, among these, are the most likely determinants of the distortions. For this reason, no effort is made to assemble direct evidence on their distribution across countries and compare it to the distribution of wedges inferred from the dispersion of relative prices.

Hsieh and Klenow (2003) have used a version of the two-sector neoclassical growth model to discriminate among a few possible explanations of the key development regularities. They have considered cross-country differences in saving propensities, in explicit taxes or tariffs specific to investment goods, in capital income taxes, and in sectoral TFPs. Their conclusion is that the development regularities are only consistent with rich countries being more productive (having an absolute advantage) and having a comparative advantage in the production of investment goods. Taxes and tariffs targeting investment goods are among the wedges that fit the definition of distortion considered by Chari, Kehoe, and McGrattan (1996) and Restuccia and

\footnotetext{
${ }^{27}$ Equation (28) indicates that measured TFP is monotone increasing in the world price. This implies that while the ranking of countries with respect to measured TFP is invariant to changes in $p^{w}$, the cross-country variation in this variable is not. In turn, this means that our distributional assumption for $\xi$ matters for the magnitude of the cross-country dispersion in TFP.

${ }^{28}$ As these two papers make clear, the explicit taxation interpretation differs from the remaining interpretations in that the aggregate resource constraint remains unchanged in the former case, but not in the latter. This difference, however, does not affect the implications for the variables of interest in a significant way.
} 
Urrutia (2001). Hsieh and Klenow (2003) notice that, investment good being widely traded across countries, their net prices (net of taxes and tariffs) should be fairly similar across countries. Hence, there should be a tendency for gross prices to be higher in less developed countries. This prediction appears to be counterfactual. The prices reported in the Penn World Tables, which are gross of all explicit taxes, do not tend to be negatively associated with incomes.

Hsieh and Klenow's (2003) work leaves the remaining investment wedges (all but taxes and tariffs) and sectoral TFP differences as candidate explanations. In the context of Hsieh and Klenow's (2003) setup, it is impossible to tell them apart, because their implications for macro aggregates are identical. If we denote the sectoral TFPs as $A_{C}$ and $A_{I}$ and the investment wedge as $\theta$, their model implies that the relative price of investment goods is $P_{I} / P_{C}=(1+\theta) A_{C} / A_{I} \cdot{ }^{29}$ One can also easily show that the whole equilibrium allocation is a function of the composite term $(1+\theta) A_{C} / A_{I}$. It follows that macro observations cannot help us distinguishing the role of cross-country variation in $A_{C} / A_{I}$ from that of cross-country variation in $\theta \cdot{ }^{30}$

In order to make progress towards understanding why certain countries face higher prices of capital and invest less, we need to understand what these investment wedges really are. At the very least, this is a necessary condition for formulating policy recommendations. In turn, this objective can only be accomplished by studying microfounded models. This is exactly what we do in this paper. Micro-foundations are needed because they allow for falsification. Our exercise highlights why this is the case. Not only must it be the case that the parameter $\xi$ belongs to the interval $[0,1]$. Tying the investment wedge to the level of investor protection and to the variation in idiosyncratic risk, our theory generate two further restrictions: (i) the distribution of $\xi$ must be consistent with the cross-country evidence on the quality of institutions and (ii) the levels of idiosyncratic risk in the consumption and investment good sectors must agree with the data presented in Section 2. ${ }^{31}$ The test for our mechanism is to generate sizeable variation in investment rates and relative prices while satisfying

\footnotetext{
${ }^{29}$ This is true provided that (i) the technologies display constant returns to scale and are identical across sectors up to a multiplicative TFP parameter, (ii) input markets are perfectly competitive, and (iii) inputs are perfectly mobile across sectors.

${ }^{30} \mathrm{~A}$ similar observation applies to our model. Assume $\xi=0$, so that investor protection is perfect in all countries. Suppose also that investment good producers need to pay $(1+\theta)(r+\delta)$ for each unit of capital they rent. Then it is easy to establish that $p=(1+\theta)^{\alpha} \bar{z}_{C} / \bar{z}_{I}$. Because of decreasing returns to scale in production, however, the allocation is not a function of a composite term of $1+\theta$ and $\bar{z}_{C} / \bar{z}_{I}$. In spite of this, variation in $\theta$ and in $\bar{z}_{C} / \bar{z}_{I}$ still generate qualitatively identical implications for the variables of interest.

${ }^{31}$ Notice that these restrictions bind. If, contrary to the evidence presented in Section 8, idiosyncratic risk was higher in the consumption good sector, our model would predict that poor countries face lower relative prices of capital!
} 
these restrictions. We will get to that in Section 8 .

\section{International Trade}

So far we have proceeded under the assumption of closed economy. Do our conclusions change if we allow for international trade and for international capital flows? If yes, how? This section is devoted to answering these questions.

\subsection{Intra-temporal Trade}

If investment goods are fully tradable while consumption goods are not, and borrowing and lending is not allowed, then the predictions characterized in Sections 4 and 6 stand intact. In this scenario, the absolute domestic price of the investment good equals the price prevailing in international markets, but there is no trade in equilibrium. Our model still pins down the relative price (i.e. the absolute price of the consumption good) and the comparative statics is unchanged. In particular, the model still predicts that the relative price of capital goods is negatively associated with investor protection. The novelty is that its variation is uniquely due to the variation in the absolute price of consumption goods, which will be lower, the poorer investor protection (and income per worker). As already noted, this is consistent with the data.

If we also allowed for trade in consumption goods, the domestic relative price would be tied to its world-wide level. Countries would specialize. Those with low $\xi$ (relative to a threshold determined by the world's equilibrium relative price of investment) would produce only investment goods, whereas those with relatively high $\xi$ would specialize in consumption goods. The empirical evidence shows that most investment goods are tradeable, while many consumption goods are not. Among the latter are many services. What would happen then, if we assumed one investment good and two consumption goods, of which one tradable and the other not? Countries would end up producing either one of the tradable goods, along with the non-tradable one. Within the countries producing investment goods (those with better legal institutions), differences in investor protection would still generate variation in the relative price of investment goods. However, this would not be the case within countries producing the tradeable consumption. For them, any variation in the relative price of investment would originate in cross-country differences in productivity in the traded consumption good sector relative to productivity in the non-traded consumption good sector. A further implication of allowing for a perfectly tradeable consumption good is that even though the relative price of investment would still vary across countries, 
there would be no variation in the price of investment relative to tradable consumption. This appears to be counterfactual. Hsieh and Klenow (2003) provide evidence suggesting that the price of investment relative to the price of tradable consumption does covary with income, although less than the price of investment relative to the price of total consumption. ${ }^{32}$

Our conclusion is that free trade is probably not a sensible assumption. As long as there are some impediments to trade, the mechanism outlined in the previous sections for closed economies produces the same qualitative results for open economies.

\subsection{Intertemporal Trade}

We now consider the case of free capital flows. We still maintain that only capital goods are tradable, but we allow domestic financial intermediaries to lend and borrow capital from the rest of the world at the interest rate prevailing abroad. In this version of our model, the capital stock owned by domestic entrepreneurs (the national capital $K_{t}^{S}$ ) will be different from the capital employed by domestic agents (the domestic

capital $K_{t}^{D}$ ). The difference $K_{t}^{S}-K_{t}^{D}$ is the net outflow of capital to the rest of the world.

Notice that since the consumption good cannot be traded or stored, domestic consumption must equal domestic production of consumption goods. ${ }^{33}$ Now assume for simplicity that the world-wide interest rate is constant at the level $r$. In this scenario, no matter its initial value $K_{0}^{S}$, the economy will jump to the steady state. For this reason, we drop time indexes. The relative price $p$ and relative size $Q$ are independent of the interest rate and can be recovered as in Section 4. Then the necessary condition for contract optimality in the consumption good sector yields $k_{C}$ and therefore $k_{I}$. Imposing equality between domestic consumption and domestic production of consumption goods pins down the fraction of agents in the investment good sector.

Poorer protection is associated with an outflow of capital, i.e. $K^{S}>K^{D}$, and a trade balance surplus: financial intermediaries in poor-protection countries invest their clients' savings abroad and use the factor payment to purchase new capital from foreign producers. The current account is in equilibrium: the trade balance equals net factor income from abroad. To see this, write GDP in domestic prices as the sum

\footnotetext{
${ }^{32}$ In particular, we refer to Table 4 of their paper, which shows that the absolute price of nontradable consumption (essentially services) still correlates positively with income.

${ }^{33}$ The definition of equilibrium is the obvious modification of Definition 1 and is omitted for the sake of brevity.
} 
of consumption, investment, and the trade balance:

$$
Y \equiv(1-N) \bar{z}_{C} k_{C}^{\alpha}+p \delta K^{s}+p\left[N \bar{z}_{I} k_{I}^{\alpha}-\delta K^{s}\right]
$$

Then express it as the sum of the incomes distributed to entrepreneurs and factor owners:

$$
Y \equiv p \frac{K^{S}}{\kappa(r)}+p(r+\delta) K^{D}
$$

Since the consumption good market clears, imposing that the two expressions above be equal and realizing that $p\left(K^{s}-K^{d}\right)(r+\delta)$ is net factor income from abroad, yields the result.

It is immediate to show that $k_{C}, k_{I}$ and $N$ all fall when $\xi$ increases. Numerical experiments indicate that the qualitative responses of all other variables to changes in investor protection are the same as in Sections 4 and 6. Figure 7 illustrates this result. The figure also hints that when capital flows are allowed for, the responses of most variables are starker.

This is due to differences in the elasticity of capital supply. In the closed economy case, such elasticity is positive and finite. Via its negative effect on entrepreneurs' demand for capital, poorer protection implies a lower interest rate, and therefore a redistribution of resources from agents with low propensity to save (the elderly) to agents with higher propensity (the young). ${ }^{34}$ In the open economy case instead, the elasticity of capital supply is infinite.

\section{Quantitative Assessment}

Having fully characterized the qualitative implications of our model, we now ask whether it can account for a sizeable fraction of the cross-country dispersion in relative investment prices and PPP investment rates. To answer this question, we examine the joint cross-country distribution of prices and investment rates induced by the calibration procedure described in Section 5. Our methodology involves assuming the existence of a continuum of countries, identical in every respect but the level of investor protection. The parameter $\xi$ is assumed to be uniformly distributed across countries, over its natural domain $[0,1]$.

The joint distribution is illustrated by the solid line in Figure 8. Such line is simply the locus of relative investment prices and PPP investment rates predicted by the

\footnotetext{
${ }^{34}$ See Castro, Clementi, and MacDonald (2004) for a careful description of this mechanism.
} 

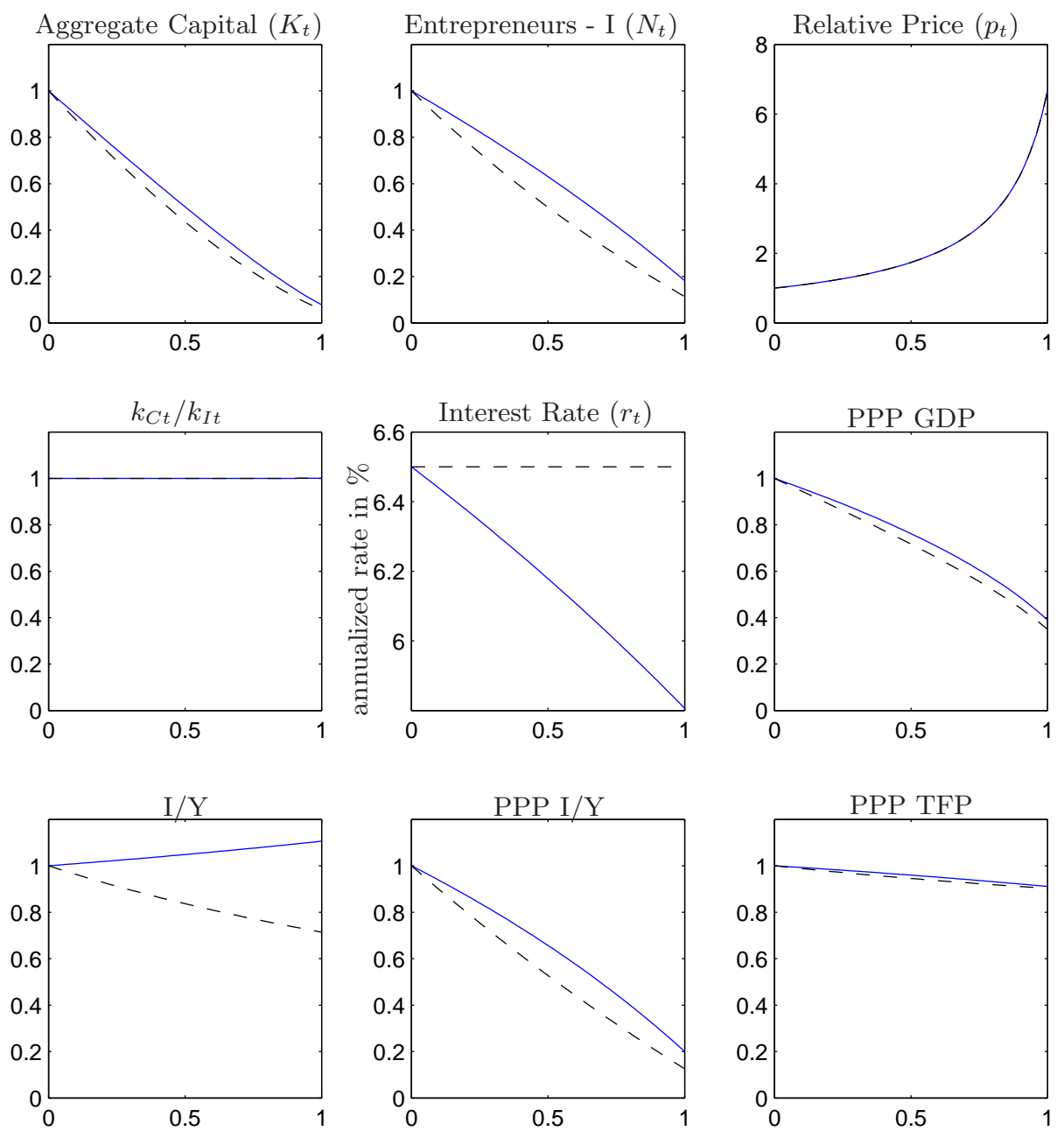

Figure 7: Steady-State Values for $\xi \in[0,1]$ (solid line = closed economy; dashed line = open economy).

model, relative to the US values. For the purpose of comparison, it is superimposed on the scatter plot of the data. The extreme point of the line to the North-West represents the country with the best investor protection, which we associate with the United States. The extreme point to the South-East identifies the country with the poorest investor protection.

Recall from Section 5 that the choices of all parameter values but one are based upon either independent micro evidence or long-run information not directly related to the cross-country dispersion. The sole exception is the mean parameter $\mu_{I}$, which we pick so that the model generates a cross-country variation in relative prices equal to the value implied by the 1996 Penn World Table.

The object of interest is the cross-country dispersion in investment rates that our model generates. We find that the standard deviation of investment rates is equal to 
$43 \%$ of the value that emerges from the 1996 Penn World Table.

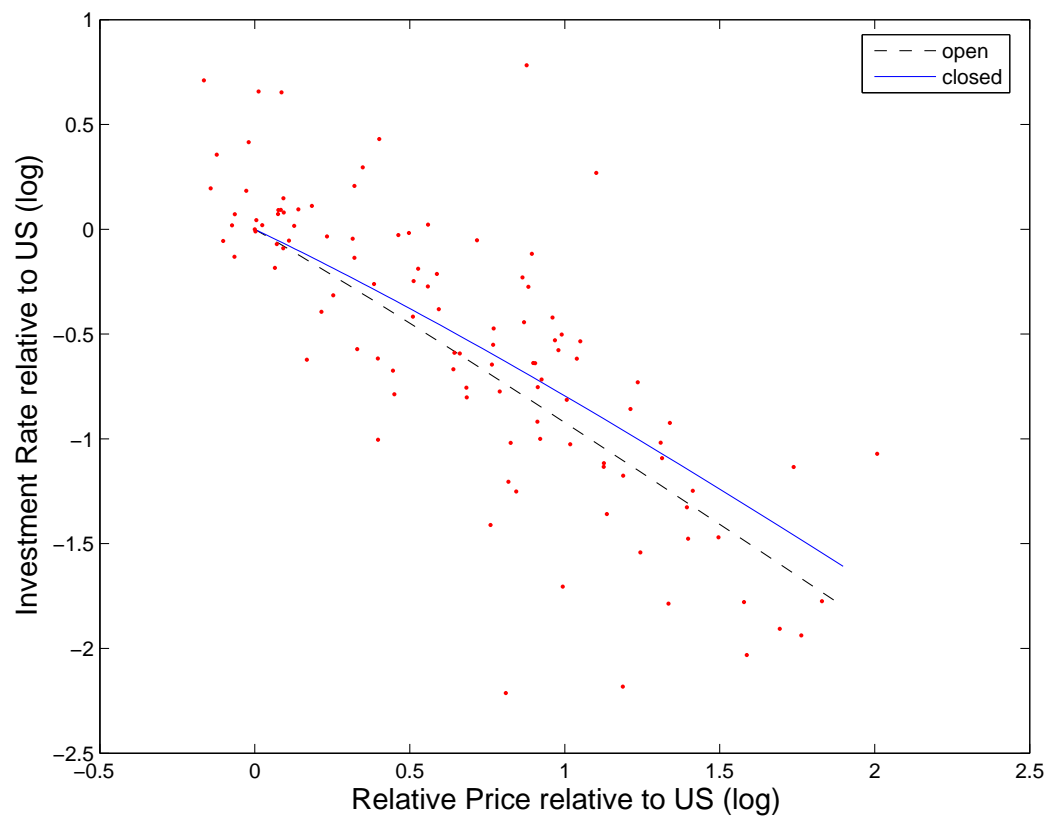

Figure 8: Dispersion in Relative Prices and PPP Investment Rates.

The dashed line is the relative price-investment rate locus implied by the model under free capital flows. ${ }^{35}$ Consistently with what argued in Section 7, the response of capital accumulation to changes in investor protection is stronger. The model can account for $55 \%$ of the variation in investment rates. ${ }^{36}$

Our simple exercise hints that cross-country differences in legal institutions may account for a significant share of the observed dispersion in relative prices and investment rates. Unfortunately, the parsimony of our setup prevents us from being more ambitious. A more general environment would allow for a better match between theory and data. We find it particularly unfortunate that, as already argued in Section 5 , our model does not allow for a tighter match between the parameters of the productivity distributions and the moments of the empirical sales growth distribution. This issue could be addressed simply by letting entrepreneurs operate for more than

\footnotetext{
${ }^{35}$ Rather than explicitly solving for the world equilibrium, we assume that the interest is equal to the US value. Since the equilibrium prices do not depend on the level of the interest rate, the price dispersion is the same in the cases of autarky and trade. Only the dispersion in investment rates is different.

${ }^{36}$ When the model is re-calibrated to accommodate $\alpha=0.2$, the closed and open economy models account for $51 \%$ and $57 \%$ of the volatility, respectively.
} 
one period. We have not pursued this route because it would result in a much less clean characterization of the contracting problem. ${ }^{37}$

So far, the only restriction we have imposed on the cross-country distribution of $\xi$ comes from the theory: it must be that $\xi \in[0,1]$. Can we derive further restrictions from the data? This is equivalent to asking whether we can identify an empirical counterpart to our parameter $\xi$. In the affirmative case, we could obtain direct estimates of $\xi$ to impose on our model. In recent years, several scholars have attempted to directly assess the variation in the quality of institutions across countries. These attempts involve assigning scores to countries based on the provisions of the law, their enforcement, and the distribution of powers across institutions. Among the indicators produced by this literature, those provided by La Porta, Lopez-de Silanes, Shleifer, and Vishny (1998) (LLSV from now on) appear to be the most relevant for our analysis. They are geared towards measuring the extent to which the letter of the law protects creditors' rights (the case of the $C R$ indicator) and minority shareholders' rights (indicators $O V$ and $A R$ ), and the extent to which the law is actually enforced (the $R L$ indicator). ${ }^{38}$ Unfortunately the information contained in these variables cannot be used to generate an empirical distribution of $\xi$. We believe that this is the case for two reasons. A first issue is the ordinal nature of the indicators. A second is that ex-ante we do not have elements to select one or a particular combination of indicators as the most informative about $\xi$.

In spite of our assessment that the LLSV's indicators are unsuitable for calibration purposes, we find it interesting to compare their cross-country distributions with the model-implied distribution of $\xi$. The latter object is the list of values for $\xi$ that our quantitative exercise implicitly associates with each country in the LLSV's dataset. By now it should be clear that our analysis implies a systematic association of $\xi$ with PPP investment rates and relative prices: negative in the former case and positive in the latter. In turn, this means that the empirical distributions of both relative prices and investment rates can be thought of as proxies for the distribution of $\xi$.

Table 2 reports the results of regressing relative investment prices and PPP investment rates on the LLSV's indicators. It turns out that $R L$ and $O V$ co-vary negatively

\footnotetext{
${ }^{37}$ From the appendix to Castro, Clementi, and MacDonald (2003), it can be deduced that modeling labor in our setting would be relatively straightforward. We decide not to do it, because we believe it would not alter our results and would not generate further restrictions on the the data. The reason is that the distortions induced by imperfect investor protection are sector- rather than input-specific.

${ }^{38}$ The variable $C R$ is higher, the wider the range of creditor rights in firm reorganization and liquidation upon default. The indicator anti-director rights, $A R$, and the dummy one share-one vote, $O V$, are two indices geared towards assessing the ability of small shareholders to participate in decision-making. Finally, the index rule of law, $R L$, proxies for the quality of law enforcement.
} 
Table 2: Relative Prices, Investment Rates, and Investor Protection

\begin{tabular}{lcc}
\hline \hline Dependent Variables: & Relative Price (log) & PPP Investment Rate $(\log )$ \\
\hline Rule of law (RL) & $-0.09430^{* * *}$ & $0.09611^{* * *}$ \\
& $(0.01129)$ & $(0.01610)$ \\
One share-one vote (OV) & $-0.20344^{* *}$ & $0.35406^{* *}$ \\
& $(0.07628)$ & $(0.14892)$ \\
Antidirector rights (AR) & 0.01289 & -0.02079 \\
& $(0.02372)$ & $(0.04141)$ \\
Creditor rights (CR) & 0.04844 & -0.01924 \\
& $(0.02979)$ & $(0.04094)$ \\
Constant & $0.66282^{* * *}$ & $2.32723^{* * *}$ \\
& $(0.12289)$ & $(0.19778)$ \\
\hline Number of countries & 46 & 46 \\
Adjusted $R^{2}$ & 0.538 & 0.323 \\
\hline Note: White robust standard errors in parenthesis. \\
Sources: Heston, Summers, and Aten (2002) and La Porta, Lopez-de Silanes, \\
Shleifer, and Vishny (1998). \\
*** Significant at 1\%; ${ }^{* *}$ Significant at 5\%.
\end{tabular}

with our proxies for $\xi$, whereas $C R$ and $A R$ are not significantly correlated with them. This suggests that among the measures of investor protection considered by LLSV, law enforcement is the one that is likely to matter the most for risk-sharing.

\section{Extensions}

Our simple model illustrates how, in the presence of cross-sectoral differences in idiosyncratic risk, changes in investor protection may cause the reallocation of factors (entrepreneurs and capital) across consumption and investment good sectors, giving rise to changes in relative prices and investment rates. In order to best clarify the working of this mechanisms, we have disregarded other important margins along which actual economies may adjust to changes in risk-sharing brought about by institutional differences. In this section we briefly discuss some of these margins and we argue that considering them could help understanding other facets of economic development.

To start with, we have abstracted completely from ex-ante differences in entrepreneurial ability. Accounting for the fact that people are born with different skills may be important. In fact, our analysis of Section 2 has uncovered a non-negligible amount of heterogeneity in firm fixed-effects, which could reasonably be interpreted as ex-ante differences in ability. ${ }^{39}$ In Appendix D we we accommodate ex-ante heterogeneity by assuming that agents are equally successful in the consumption good

\footnotetext{
${ }^{39}$ It is still the case, however, that in nearly all sectors we look at, residual uncertainty accounts for a substantially larger share of sales growth variance compared to firm fixed-effects. This suggests it may in fact be reasonable to abstract from ex-ante uncertainty.
} 
sector, but differ in their ability to manage technologies in the investment good sector. The allocation of skill across sectors becomes a function of investor protection. A decrease in investor protection can lead to the reallocation of individuals away from the sector where they enjoy a comparative advantage. In turn, this can result in greater effects on investment rates, income, and measured TFP. ${ }^{40}$

Now think of heterogeneity in capital goods. As already noted in Section 2, Eaton and Kortum (2001), among others, distinguish between equipment and structures. They find that the production of equipment is concentrated in a few countries, which turn out to be among those with better investor protection. If equipment goodsproducing firms face higher idiosyncratic risk - as it seems quite reasonable in the case of electronics and other high-tech products - a version of the open-economy model presented in Section 7, amended to allow for heterogeneous capital goods, would yield predictions consistent with their finding. Countries endowed with relatively better institutions would specialize in the production of riskier goods. Certain high-tech, high-risk equipment-producing sectors may not arise at all in countries with relatively poorer investor protection. Once again, the effects of low institutional quality would be farther-reaching than implied by our simple setup. Conventional wisdom suggests that entrepreneurial activities leading to technological innovations are also likely to be among the riskier ones. If this is the case, our theory suggests that innovative activities should be concentrated in high-investor protection countries. In turn, this means that institutions may have a long-term growth effect.

Think also of the underground economy. Most developing countries have large informal sectors. The ability to borrow from banks is often cited among the reasons that lead firms to emerge into the formal sector and start paying taxes. Credit from official sources makes entrepreneurs visible. Better investor protection, by improving risk-sharing, may increase the incentive to abandon the informal sector.

Finally, a key element of our analysis is the interaction between the sources of cross-country variation (in investor protection) and of cross-sectoral variation. For our argument to go through, the marginal effect of decreasing investor protection must be larger in investment-good producing sectors. In this paper we have focused on a particular type of cross-sectoral variation (in idiosyncratic risk) and we have shown that, when introduced in a fairly standard model of capital accumulation, it satisfies the requirement. We realize that considering other forms of cross-sectoral

\footnotetext{
${ }^{40}$ Alternatively to our approach, one could assume that individual skill levels constitute private information, thereby introducing adverse selection on top of moral hazard. Although we believe such a framework is potentially very interesting, we think that its analysis is beyond the scope of this paper.
} 
variation may lead to similar results. According to Rajan and Zingales (1998), firms engaged in the production of investment goods need to rely on external finance to a larger extent than their counterparts producing consumption goods. ${ }^{41}$ This may be the case, we conjecture, because they tend to incur larger initial sunk costs. We think that it is possible to model this alternative form of heterogeneity in such a way that entrepreneurs in investment good sectors are able to finance themselves at a relative lower cost in countries characterized by better investor protection. Besides representing an interesting exercise on its own, constructing such model would give us the chance to contrast the explanatory power of the two types of heterogeneity.

\section{Conclusion}

We introduced investor protection in a simple model of firm finance with asymmetric information and risk-averse entrepreneurs, along the lines of Castro, Clementi, and MacDonald (2004). In this framework it is easy to show that the poorer the protection, the lesser the risk-sharing achieved by entrepreneurs and the lower the resources they obtain from outside investors. Imbedding such model of firm finance in a general equilibrium two-sector model of capital accumulation allowed us to characterize the implications of different levels of investor protection for aggregate variables such as per-capita income, investment rates, and relative prices. We also provided novel empirical evidence, indicating that firm-level idiosyncratic risk is higher in investmentgood producing industries. Imposing this restriction on the model, we showed that imperfect investor protection induces a wedge between the rates of return on investment in the two sectors. Such wedge entails an inefficiency in the competitive allocation, distracting resources away from the investment good sector and towards the consumption good sector. In turn, this implies an increase in the relative price of capital and a decrease in the investment rate and, ultimately, income. Importantly, the size of the inefficiency and its effect on relative price, investment rate, and income, is larger, the poorer the investor protection. Our main conclusion is that the cross-country variation in the quality of the legal institutions that safeguard investors' rights may be responsible for generating the observed correlation between income per worker, relative price of capital, and investment rate.

We see our paper as contributing to an important line of research that tries to understand why countries have such widely different development experiences. We

\footnotetext{
${ }^{41}$ This is not exactly the classification adopted by the authors. However, even a cursory look at their data reveals that investment-good producing sectors tend to be classified as sectors in which firms require larger access to external finance.
} 
have proposed a micro-founded model that features an explicit link between the quality of institutions, sectoral differences in idiosyncratic volatility, and macroeconomic outcomes. Our analysis shows that this mechanism can account for several important aspects of the cross-country variation in development experiences. Our emphasis on micro-foundations brings several advantages. Most importantly, it yields restrictions that are very helpful in assessing the validity of the model. 


\section{A Data}

Our data draws from the COMPUSTAT North-America Industrial Annual Database from 1950 to 2005. After dropping all observations for which either net sales, employment, or the NAICS code are missing, our dataset consists of 265,018 firm-year observations. We then proceed to delete all firms that have less than 3 observations and those belonging to 3-digit NAICS sectors for which the yearly average number of firms in the sample is less than 4 . We also eliminate all firm-year observations which are affected by a merger or acquisition since the previous year, and those for which the COMPUSTAT has indicated a potential accounting problem in net sales. Finally, we drop all firms in the Finance and Insurance (3-digit NAICS from 520 to 529), Utilities (220 to 229), and Real Estate (531) industries. We also drop the firms classified by COMPUSTAT in the 3-digit sector 999, which turns out to be a residual category. COMPUSTAT classifies some firms according to the 1997 NAICS system and others according to the 2002 NAICS system. We used the equivalence tables between the two systems published by the BEA to assign every 2002 NAICS code to a corresponding 1997 NAICS code (for example, most firms categorized by COMPUSTAT in sector 236 are included in 233, and all of those in sector 423 are attributed to 421$)$.

Next, we label each of the remaining sectors as either consumption or investment good producing. Our procedure is very similar to the one described in Appendix 2 of Chari, Kehoe, and McGrattan (1996). We rely on the Bureau of Economic Analysis' 1997 Benchmark Input-Output Use Summary Table for the US. The Use Table tells us the fraction of output that flows from each 3-digit sector to any of the other 3-digit industries and to final demand, respectively. We first group final demand uses into two categories, consumption $(C)$ and investment $(I)$. We do this by aggregating personal, federal, and state consumption expenditures into a single consumption category, and similarly for investment expenditures. Since the Use Table does not provide a breakdown of imports, exports, and changes in inventories into consumption and investment, we choose to ignore these final demand items. Now denote by $A$ the square matrix of unit input-output coefficients. This matrix can be easily constructed from the original Use Input-Output Matrix by normalizing each row by the total commodity column. Then define the total consumption and investment output of the different sectors by

$$
Y_{C}=A Y_{C}+C \Leftrightarrow Y_{C}=\left(I_{s}-A\right)^{-1} C
$$


and

$$
Y_{I}=A Y_{I}+I \Leftrightarrow Y_{I}=\left(I_{s}-A\right)^{-1} I
$$

respectively, where $I_{s}$ is an identity matrix and $s$ is the number of sectors. This means that we include in the consumption output of a given sector all the intermediate good products whose ultimate destination is final consumption, and similarly for investment. Finally, for each 3-digit industry $j$, we compute the share of output destined to consumption, $Y_{C}(j) /\left(Y_{C}(j)+Y_{I}(j)\right)$. We assign all industries with a share greater than or equal to $60 \%$ to the consumption good sector, and those with a share lower than or equal to $40 \%$ to the consumption good sector. We discard the remaining industries.

A the end of this process we are left with an unbalanced panel of 8,078 firms, distributed in 60 sectors, for a total of 81,454 firm-year observations. For each sector, Table 3 reports value added as a fraction of GDP as evinced from the Input-Output Table, and the fraction of output ultimately destined to consumption. Table 4 reports the yearly average number of firms per sector and the results of the estimation of equations (1) and (2).

We carried out a variety of robustness checks. We repeated the analysis by deleting all firm-year observations in which an IPO took place. As expected, the volatility estimates decrease, but they do so across the board, leaving our results on the relative volatility intact. Finally, we also experimented with alternative specifications of the regression equation (1). In particular, we introduced a firm-specific time trend, in order to control for trends in the growth process that are not captured by either age or size. It turns out that adding these factors adds very little to the predictive power of the equation, therefore leaving our results unchanged. 
Table 3: Summary Statistics

\begin{tabular}{|c|c|c|c|}
\hline NAICS & Description & Value Added (\%) & Cons. Share $(\%)$ \\
\hline \multicolumn{4}{|c|}{ Investment Sectors } \\
\hline 213 & Support Activities for Mining & $0.13^{42}$ & 12.55 \\
\hline 233 & Building, Developing, and General Contracting & $3.61^{43}$ & 10.49 \\
\hline 234 & Heavy Construction & 3.61 & 10.49 \\
\hline 235 & Special Trade Contractors & 3.61 & 10.49 \\
\hline 321 & Wood Product Manufacturing & 0.31 & 39.97 \\
\hline 333 & Machinery Manufacturing & 1.21 & 19.50 \\
\hline 334 & Computer and Electronic Product Manufacturing & 1.96 & 35.72 \\
\hline \multicolumn{4}{|c|}{ Consumption Sectors } \\
\hline 111 & Crop Production & 0.79 & 96.75 \\
\hline 211 & Oil and Gas Extraction & 0.44 & 85.10 \\
\hline 212 & Mining (except Oil and Gas) & 0.30 & 63.98 \\
\hline 311 & Food Manufacturing & 1.21 & 99.02 \\
\hline 312 & Beverage and Tobacco Product Manufacturing & 0.60 & 99.60 \\
\hline 313 & Textile Mills & 0.18 & 87.75 \\
\hline 314 & Textile Product Mills & 0.12 & 80.45 \\
\hline 315 & Apparel Manufacturing & 0.29 & 99.40 \\
\hline 316 & Leather and Allied Product Manufacturing & 0.04 & 96.20 \\
\hline 322 & Paper Manufacturing & 0.58 & 84.01 \\
\hline 323 & Printing and Related Support Activities & 0.51 & 88.51 \\
\hline 324 & Petroleum and Coal Products Manufacturing & 0.24 & 83.71 \\
\hline 325 & Chemical Manufacturing & 1.65 & 83.15 \\
\hline 326 & Plastics and Rubber Products Manufacturing & 0.73 & 69.10 \\
\hline 339 & Miscellaneous Manufacturing & 0.57 & 75.65 \\
\hline 421 & Wholesale Trade, Durable Goods & $5.88^{44}$ & 69.35 \\
\hline 422 & Wholesale Trade, Nondurable Goods & 5.88 & 69.35 \\
\hline 441 & Motor Vehicle and Parts Dealers & $5.72^{45}$ & 89.80 \\
\hline 442 & Furniture and Home Furnishings Stores & 5.72 & 89.90 \\
\hline 443 & Electronics and Appliance Stores & 5.72 & 89.80 \\
\hline 444 & Building Material and Garden Equipment & 5.72 & 89.80 \\
\hline 445 & Food and Beverage Stores & 5.72 & 89.80 \\
\hline 446 & Health and Personal Care Stores & 5.72 & 89.80 \\
\hline 448 & Clothing and Clothing Accessories Stores & 5.72 & 89.80 \\
\hline
\end{tabular}

\footnotetext{
${ }^{42}$ Data on value added is drawn from the 1997 Use Summary Table.

${ }^{43}$ This figure refers to the aggregate of the I-O Tables' categories "New Residential Construction", "New Nonresidential Construction", and "Maintenance and Repair Construction".

${ }^{44}$ This figure refers to the "Wholesale Trade" category. The I-O Tables do not disaggregate it further.

${ }^{45}$ This figure refers to the "Retail Trade" category. The I-O Tables do not disaggregate it further.
} 
Table 3: (continued)

\begin{tabular}{|c|c|c|c|}
\hline NAICS & Description & Value Added (\%) & Cons. Share $(\%)$ \\
\hline \multicolumn{4}{|c|}{ Consumption Sectors } \\
\hline 451 & Sporting Goods, Hobby, Book, and Music Stores & 5.72 & 89.80 \\
\hline 452 & General Merchandise Stores & 5.72 & 89.80 \\
\hline 453 & Miscellaneous Store Retailers & 5.72 & 89.80 \\
\hline 454 & Nonstore retailers & 5.72 & 89.80 \\
\hline 481 & Air Transportation & 0.53 & 85.28 \\
\hline 482 & Rail Transportation & 0.28 & 73.99 \\
\hline 483 & Water Transportation & 0.07 & 85.68 \\
\hline 484 & Truck Transportation & 0.97 & 71.92 \\
\hline 486 & Pipeline Transportation & 0.10 & 87.54 \\
\hline 488 & Support Activities for Transportation & $0.25^{46}$ & 79.96 \\
\hline 492 & Couriers and Messengers & 0.30 & 78.89 \\
\hline 512 & Motion Picture and Sound Recording Industries & 0.31 & 97.44 \\
\hline 513 & Broadcasting and Telecommunications & 2.38 & 88.68 \\
\hline 514 & Information and Data Processing Services & 0.36 & 81.83 \\
\hline 532 & Rental and Leasing Services & 0.67 & 83.65 \\
\hline 533 & Owners and Lessors of Nonfinancial Assets & 1.18 & 79.14 \\
\hline 541 & Professional, Scientific and Technical Services & 6.20 & 67.91 \\
\hline 561 & Administrative and Support Services & 2.69 & 80.80 \\
\hline 562 & Waste Management and Remediation Services & 0.27 & 83.88 \\
\hline 611 & Educational Services & 0.75 & 98.12 \\
\hline 621 & Ambulatory Health Care Services & 3.15 & 99.98 \\
\hline 622 & Hospitals & 1.82 & 100.00 \\
\hline 623 & Nursing and Residential Care Facilities & 0.69 & 100.00 \\
\hline 711 & Performing Arts, Spectator Sports, ... & 0.36 & 93.26 \\
\hline 713 & Amusement, Gambling, and Recreation Industries & 0.54 & 98.62 \\
\hline 721 & Accommodation & 0.92 & 92.45 \\
\hline 722 & Food Services and Drinking Places & 1.79 & 96.96 \\
\hline 811 & Repair and Maintenance & 0.95 & 85.06 \\
\hline 812 & Personal and Laundry Services & 0.67 & 98.73 \\
\hline
\end{tabular}

\footnotetext{
${ }^{46}$ This figure refers to the I-O Tables' category "Sightseeing Transportation and Transportation Support".
} 
Table 4: Estimates

\begin{tabular}{|c|c|c|c|c|}
\hline NAICS & $\ln (s i z e)$ & $\ln (a g e)$ & volatility (ranking) & avg \# firms \\
\hline \multicolumn{5}{|c|}{ Investment Sectors } \\
\hline 213 & -.0031302 & .0085014 & $.0659157(27)$ & 10 \\
\hline 233 & .0098189 & .0137877 & $.1056476(11)$ & 14 \\
\hline 234 & $.082332^{* * *}$ & $-.1942279^{* *}$ & $.1245035(5)$ & 6 \\
\hline 235 & .0033294 & .0130888 & $.0584632(34)$ & 6 \\
\hline 321 & $-.0743625^{* * *}$ & -.0137304 & $.0836557(17)$ & 15 \\
\hline 333 & $-.0220547^{* * *}$ & $-.111267^{* * *}$ & $.0888356(16)$ & 100 \\
\hline 334 & $-.0611239^{* * *}$ & $-.1653497^{* * *}$ & $.1152213(9)$ & 255 \\
\hline \multicolumn{5}{|c|}{ Consumption Sectors } \\
\hline 111 & $-.1939484^{* * *}$ & $-.3041054^{* * *}$ & $.0744715(24)$ & 4 \\
\hline 211 & .0086768 & $-.245898^{* * *}$ & $.1542846(2)$ & 64 \\
\hline 212 & $.0881622^{* * *}$ & $-.15899^{* *}$ & $.1360758(4)$ & 23 \\
\hline 311 & $-.0250951^{* * *}$ & $-.0890859^{* * *}$ & $.0489535(37)$ & 45 \\
\hline 312 & -.0025538 & $-.0378842^{*}$ & $.0515543(36)$ & 13 \\
\hline 313 & -.003285 & -.0104182 & $.0548013(35)$ & 14 \\
\hline 314 & .0087065 & $-.0952713^{* *}$ & $.0444377(41)$ & 4 \\
\hline 315 & $-.0745512^{* * *}$ & $-.106125^{* * *}$ & $.0650508(28)$ & 25 \\
\hline 316 & $-.0760973^{* * *}$ & $-.063782^{* * *}$ & $.035551(48)$ & 11 \\
\hline 322 & $-.0353021^{* * *}$ & -.0101161 & $.0416634(43)$ & 26 \\
\hline 323 & .0167837 & $-.0448362^{* * *}$ & $.0430462(42)$ & 14 \\
\hline 324 & -.0173259 & .0125759 & $.0488046(38)$ & 22 \\
\hline 325 & -.0163228 & $-.114327^{* * *}$ & $.1197231(6)$ & 141 \\
\hline 326 & .0021413 & $-.0589135^{* * *}$ & $.0638843(30)$ & 29 \\
\hline 339 & -.0169723 & $-.1712456^{* * *}$ & $.0952873(14)$ & 54 \\
\hline 421 & -.0069892 & $-.0977216^{* * *}$ & $.0812233(18)$ & 52 \\
\hline 422 & $-.0453721^{* * *}$ & $-.0646109^{* * *}$ & $.0763564(22)$ & 29 \\
\hline 441 & .0691165 & $-.1722535^{* * *}$ & $.0063206(60)$ & 4 \\
\hline 442 & $-.0933022^{* * *}$ & $-.0654218^{*}$ & $.0160526(57)$ & 5 \\
\hline 443 & $-.041673^{* * *}$ & $-.114911^{* * *}$ & $.0381181(44)$ & 6 \\
\hline 444 & -.002398 & $-.0944098^{* * *}$ & $.0282685(55)$ & 7 \\
\hline 445 & $-.0118256^{*}$ & $-.0275481^{* * *}$ & $.0308973(52)$ & 21 \\
\hline 446 & $-.104086^{* * *}$ & $-.0804354^{* * *}$ & $.0361896(46)$ & 9 \\
\hline 448 & $-.0416039^{* * *}$ & $-.0577344^{* * *}$ & $.0449255(40)$ & 22 \\
\hline 451 & -.0122337 & $-.0645347^{* * *}$ & $.0341598(50)$ & 10 \\
\hline 452 & $-.012334^{*}$ & $-.0380349^{* * *}$ & $.037139(45)$ & 15 \\
\hline 453 & -.0345285 & $-.2197272^{* * *}$ & $.0353205(49)$ & 5 \\
\hline 454 & $.1106638^{* * *}$ & $-.1841804^{* *}$ & $.1192932(7)$ & 11 \\
\hline
\end{tabular}

Firm fixed effects and sectoral time dummies omitted.

*** Significant at $1 \% ;{ }^{* *}$ Significant at $5 \%$; ${ }^{*}$ Significant at $10 \%$. 
Table 4: (continued)

\begin{tabular}{|c|c|c|c|c|}
\hline NAICS & $\ln ($ size $)$ & $\ln ($ age $)$ & volatility (ranking) & avg \# firms \\
\hline \multicolumn{5}{|c|}{ Consumption Sectors } \\
\hline 481 & $-.0737513^{* * *}$ & $-.1017634^{* * *}$ & $.0604847(32)$ & 21 \\
\hline 482 & $-.0611843^{* * *}$ & $-.0550491^{* * *}$ & $.0292518(53)$ & 11 \\
\hline 483 & -.0014021 & -.0636376 & $.0617857(31)$ & 8 \\
\hline 484 & $-.018733^{* * *}$ & $-.0526791^{* * *}$ & $.0268505(56)$ & 14 \\
\hline 486 & $-.056379^{* *}$ & -.0527639 & $.0481686(39)$ & 7 \\
\hline 488 & $-.0610611^{* *}$ & $-.1219306^{* * *}$ & $.006529(59)$ & 5 \\
\hline 492 & $-.0848173^{* * *}$ & -.002866 & $.0318823(51)$ & 4 \\
\hline 512 & -.016782 & $-.1070248^{*}$ & $.1477931(3)$ & 13 \\
\hline 513 & $-.0973021^{* * *}$ & $-.1235676^{* * *}$ & $.064266(29)$ & 63 \\
\hline 514 & .0401507 & $-.4530637^{* * *}$ & $.1024668(13)$ & 17 \\
\hline 532 & $-.0538958^{* * *}$ & -.0461446 & $.0804803(19)$ & 11 \\
\hline 533 & .0040648 & $-.3674476^{* * *}$ & $.1557023(1)$ & 11 \\
\hline 541 & -.0104803 & $-.2146167^{* * *}$ & $.1184636(8)$ & 74 \\
\hline 561 & $-.0272675^{* *}$ & $-.2128337^{* * *}$ & $.0900958(15)$ & 23 \\
\hline 562 & -.0448732 & -.0568337 & $.1077074(10)$ & 11 \\
\hline 611 & .0574297 & $-.3823941^{* * *}$ & $.0680737(25)$ & 7 \\
\hline 621 & $-.057038^{* *}$ & $-.2820758^{* * *}$ & $.1052375(12)$ & 19 \\
\hline 622 & -.0193501 & $-.3326046^{* * *}$ & $.0157022(58)$ & 4 \\
\hline 623 & -.0520427 & .0329648 & $.0286837(54)$ & 5 \\
\hline 711 & -.0320651 & .0040742 & $.0679429(26)$ & 11 \\
\hline 713 & -.0045382 & $-.1984318^{* * *}$ & $.0787253(20)$ & 9 \\
\hline 721 & .0134744 & $-.1671984^{* * *}$ & $.0775765(21)$ & 16 \\
\hline 722 & $-.0516385^{* * *}$ & $-.1395201^{* * *}$ & $.0600027(33)$ & 33 \\
\hline 811 & -.0004886 & $-.3564935^{* * *}$ & $.036027(47)$ & 4 \\
\hline 812 & $.0758651^{*}$ & $-.1696842^{* *}$ & $.0759023(23)$ & 7 \\
\hline
\end{tabular}

Firm fixed effects and sectoral time dummies omitted.

${ }^{* * *}$ Significant at $1 \% ;{ }^{* *}$ Significant at $5 \% ;{ }^{*}$ Significant at $10 \%$.

\section{B Volatility of Firm-Level TFP growth}

In this section we run the regression equation (1) with firm-level Solow residuals in place of real sales. Our goal is to obtain some suggestive evidence on whether focusing on real sales growth instead of real TFP growth introduces a bias in our results.

The Solow residual for firm $i$ in sector $j$ at time $t$ is

$$
z_{i j t}=y_{i j t} k_{i j t}^{-\alpha} n_{i j t}^{\alpha-1}
$$


where $y_{i j t}$ is output, $k_{i j t}$ is capital, and $n_{i j t}$ is labor. We set $\alpha=1 / 3$ for all firms. Unfortunately, COMPUSTAT imposes severe limitations for constructing appropriate measures of output and inputs.

We start with output. Ideally, one would like equate it to real value-added. From COMPUSTAT, our best approximation to value-added is

$$
v a_{i j t}=\text { sales }_{i j t}-\text { salescost }_{i j t}-\text { admincost }_{i j t}+\text { laborcost }_{i j t},
$$

where sales is Net Sales (item \#12), salescost is Cost of Goods Sold (item \#41), admincost is Selling, General and Administrative Expense (item \#189), and laborcost is Labor and Related Expense (item \#42). Real value-added is simply va divided by the sector-specific price deflator.

Unfortunately, item \#42 is missing for most firms in most years. To circumvent this problem, we proceeded as follows. First, we computed average annual wages per employee in each 3-digit sector and year using data from the Quarterly Census of Employment and Wages (QCEW), published by the Bureau of Labor Statistics. Since the QCEW only adopted the 1997 NAICS classification system starting in 1990, we restricted the temporal dimension of our panel to the 1990-2005 period. Second, whenever laborcost was missing in COMPUSTAT, we imputed it by multiplying the sectoral average wage by the number of employees.

COMPUSTAT reports a few observations with negative admincost, which we discarded. Computing value-added as described above also resulted in about $12 \%$ of the observations being negative, which we also discarded.

Regarding the inputs, we equated the labor input to the number of Employees (item \#29), and the capital input to Net Property, Plant, and Equipment (item \#8) divided by the sector-specific price deflators. Both measures are clearly imperfect, most notably the one for capital: item \#8 contains the book value of capital, not its replacement value, and it incorporates accounting methods for dealing with depreciation, which might be devoid of economic interpretation. Unfortunately, COMPUSTAT's data on investment expenditures (item \#30) is not satisfactory in its treatment of acquisitions, which prevents us from using this information.

Once we computed firm-specific Solow residuals, and after applying the same sample selection criterion as in the main regression, we ended up with 26,895 firmyear observations for 4,281 firms over the 1990-2005 period, distributed in 54 sectors.

We then proceeded exactly as in Section 2, with firm-level Solow residuals (TFP) playing the role of real sales. We summarize our findings in Figure 9, which is the counterpart to Figure 3. The two figures are broadly consistent, and in particular 


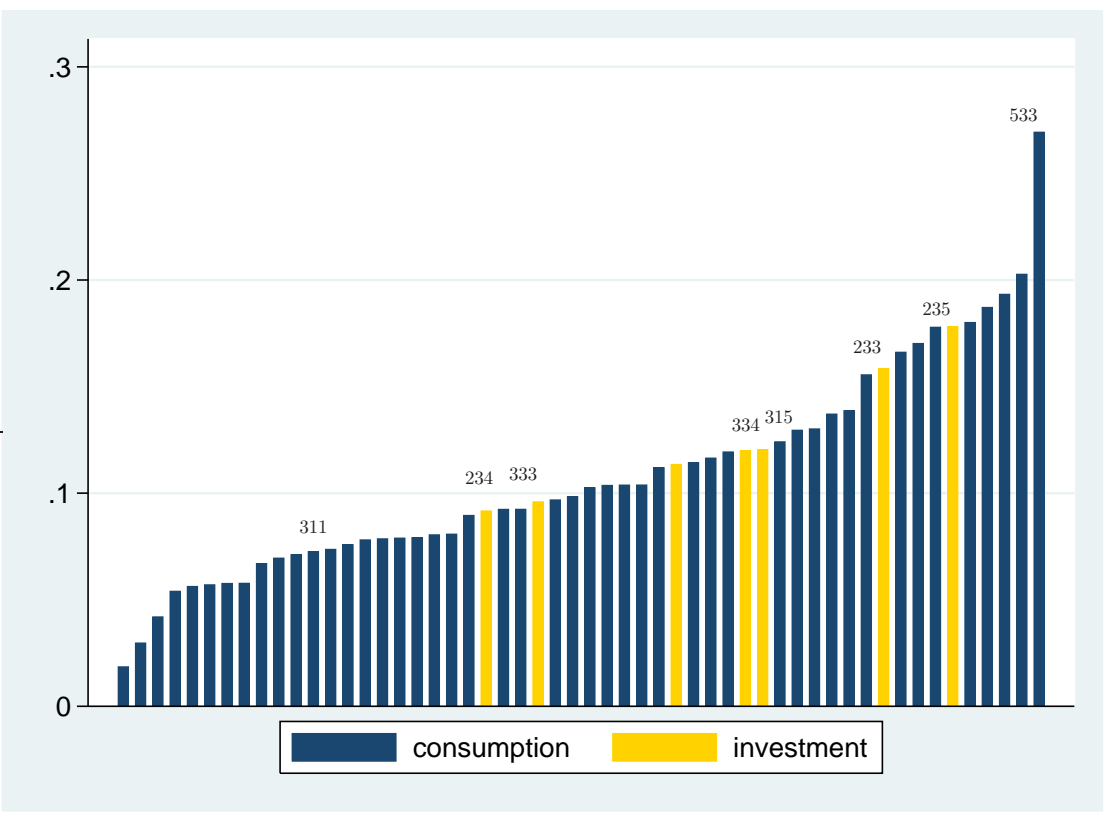

Figure 9: Volatility of TFP growth per 3-digit industry.

Figure 9 still shows investment good sectors to be among the most volatile in the economy. The comparison between the two figures therefore suggests that focusing on sales does not seem to bias our results. However, our conclusion is subject to the data shortcomings we have pointed out before. The Longitudinal Research Database (LRD), maintained by the Bureau of Census, has better data for the purposes of this exercise, although it only covers manufacturing firms. Since this data set is not publicly available, we postpone conducting our analysis on the LRD for future research.

\section{Proofs}

Lemma 1 Let $\bar{g} \equiv \rho g_{h}+(1-\rho) g_{l}$. Then $\bar{g}^{\prime} \equiv \frac{d \bar{g}}{d \xi}=-\alpha \rho(1-\rho) \Delta \frac{\omega-\xi \Delta u_{h}^{\prime} u_{l}^{\prime} \frac{\rho R_{l}+(1-\rho) R_{h}}{\left[\rho u_{h}^{\prime}+(1-\rho) u_{l}^{\prime}\right]^{2}}}{1+\alpha \rho(1-\rho) \xi \Delta u_{h}^{\prime} u_{l}^{\prime} \frac{R_{l}-R_{h}}{\left[\rho u_{h}^{\prime}+(1-\rho) u_{l}^{\prime}\right]^{2}}}>$ 0 , where $u_{i}^{\prime}=u^{\prime}\left(g_{i}\right), u_{i}^{\prime \prime}=u^{\prime \prime}\left(g_{i}\right)$, and $R_{i}=-\frac{u_{i}^{\prime \prime}}{u_{i}^{\prime}}, i=h, l$.

Proof. By definition of $g_{h}, g_{l}$, and $\omega$, it is easy to establish that $\bar{g}=(1-\alpha) \bar{z}_{I}-$ $\alpha \rho(1-\rho) \xi \Delta \omega$. Then, by the implicit function theorem, it follows that $\bar{g}^{\prime}=-\alpha \rho(1-$ $\rho) \Delta \frac{\omega+\xi \frac{\partial \omega}{\partial \xi}}{1+\alpha \rho(1-\rho) \xi \Delta \frac{\partial \omega}{\partial \bar{g}}}$. Differentiating $\omega$ with respect to $\xi$ yields $\frac{\partial \omega}{\partial \xi}=-\Delta u_{h}^{\prime} u_{l}^{\prime} \frac{\rho R_{l}+(1-\rho) R_{h}}{\left[\rho u_{h}^{\prime}+(1-\rho) u_{l}^{\prime}\right]^{2}}<$

0 . Proceeding again by differentiation, we obtain $\frac{\partial \omega}{\partial \bar{g}}=u_{h}^{\prime} u_{l}^{\prime} \frac{R_{l}-R_{h}}{\left[\rho u_{h}^{\prime}+(1-\rho) u_{l}^{\prime}\right]^{2}}$. Since CRRA preferences display non-increasing absolute risk aversion, it follows that $\frac{\partial \omega}{\partial \bar{g}}>$ 0 . 


\section{Proposition 2}

Proof. Using $g_{h}=\bar{g}+(1-\rho) \xi \Delta$ and $g_{l}=\bar{g}-\rho \xi \Delta$, we obtain $\frac{d \omega}{d \xi}=u_{l}^{\prime} u_{h}^{\prime} \frac{\bar{g}^{\prime}\left(R_{l}-R_{h}\right)-\Delta\left(\rho R_{l}+(1-\rho) R_{h}\right)}{\left[\rho u_{h}^{\prime}+(1-\rho) u_{l}^{\prime}\right]^{2}}$. Using the expression for $\bar{g}^{\prime}$ recovered in Lemma 1, we show that $\bar{g}^{\prime}\left(R_{l}-R_{h}\right)-\Delta\left(\rho R_{l}+\right.$ $(1-\rho) R_{h}<0$. This completes the proof.

Lemma $2 \frac{d}{d \xi}\left[\rho u\left(\frac{g_{h}}{\bar{z}_{I}+\rho(1-\rho) \xi \Delta \omega}\right)+(1-\rho) u\left(\frac{g_{l}}{\bar{z}_{I}+\rho(1-\rho) \xi \Delta \omega}\right)\right]>0$.

Proof. Using $g_{h}=(1-\alpha) \bar{z}_{I}-\alpha \rho(1-\rho \xi \Delta \omega+(1-\rho) \xi \Delta)$ and $g_{l}=(1-\alpha) \bar{z}_{I}-$ $\alpha \rho(1-\rho \xi \Delta \omega-\rho \xi \Delta)$, we obtain

$$
\begin{aligned}
& {\left[\bar{z}_{I}+\rho(1-\rho) \xi \Delta \omega\right]^{2} \frac{d}{d \xi}\left[\rho u\left(\frac{g_{h}}{\bar{z}_{I}+\rho(1-\rho) \xi \Delta \omega}\right)+(1-\rho) u\left(\frac{g_{l}}{\bar{z}_{I}+\rho(1-\rho) \xi \Delta \omega}\right)\right]=} \\
& =\frac{\rho(1-\rho) \bar{z}_{I} \Delta}{\left[\bar{z}_{I}+\rho(1-\rho) \xi \Delta \omega\right]^{-\sigma}}\left(u_{h}^{\prime}-u_{l}^{\prime}\right)-\frac{\rho(1-\rho) \bar{z}_{I} \Delta \omega}{\left[\bar{z}_{I}+\rho(1-\rho) \xi \Delta \omega\right]^{-\sigma}}\left[\rho u_{h}^{\prime}+\left(1-\rho u_{l}^{\prime}\right)\right] \\
& -\frac{\rho(1-\rho) \Delta \xi}{\left[\bar{z}_{I}+\rho(1-\rho) \xi \Delta \omega\right]^{-\sigma}} \frac{d \omega}{d \xi}\left[\rho\left(\bar{z}_{I}+(1-\rho) \xi \Delta\right) u_{h}^{\prime}+(1-\rho)\left(\bar{z}_{I}-\rho \xi \Delta\right) u_{l}^{\prime}\right] .
\end{aligned}
$$

Then, the observation that $\omega\left[\rho u_{h}^{\prime}+(1-\rho) u_{l}^{\prime}\right]=\left[u_{h}^{\prime}-u_{l}^{\prime}\right]$ leads to

$$
\begin{aligned}
& {\left[\bar{z}_{I}+\rho(1-\rho) \xi \Delta \omega\right]^{2} \frac{d}{d \xi}\left[\rho u\left(\frac{g_{h}}{\bar{z}_{I}+\rho(1-\rho) \xi \Delta \omega}\right)+(1-\rho) u\left(\frac{g_{l}}{\bar{z}_{I}+\rho(1-\rho) \xi \Delta \omega}\right)\right]=} \\
& =-\rho(1-\rho) \Delta \xi \frac{d \omega}{d \xi}\left[\bar{z}_{I}+\rho(1-\rho) \xi \Delta \omega\right]\left[\rho\left(\bar{z}_{I}+(1-\rho) \xi \Delta\right) u_{h}^{\prime}+(1-\rho)\left(\bar{z}_{I}-\rho \xi \Delta\right) u_{l}^{\prime}\right] .
\end{aligned}
$$

Since $\frac{d \omega}{d \xi}<0$ by Proposition 2 and $\bar{z}_{I}-\rho \xi \Delta=\rho z_{h}(1-\xi)+(1-\rho) z_{l}+\rho \xi z_{l}>0$, the above expression is positive.

\section{Proposition 3}

Proof. Solving (23) for $p$ and substituting in (24), we obtain

$$
Q=\frac{(1-\sigma)^{\frac{1}{1-\sigma}}}{1-\alpha}\left[\rho u\left(\frac{g_{h}}{\bar{z}_{I}+\rho(1-\rho) \xi \Delta \omega}\right)+(1-\rho) u\left(\frac{g_{l}}{\bar{z}_{I}+\rho(1-\rho) \xi \Delta \omega}\right)\right]^{\frac{1}{1-\sigma}}
$$

In light of Lemma 2, differentiation of the above expression immediately yields $\frac{d Q}{d \xi}>0$. Let's now turn to $\frac{d p}{d \xi}$. Taking logarithms of (23) and (24) leads to

$$
\log p=C-\alpha \log \left[\bar{z}_{I}+\rho(1-\rho) \xi \Delta \omega\right]-\frac{1-\alpha}{1-\sigma} \log \left[\rho u_{h}+(1-\rho) u_{l}\right],
$$

where $C=\log z_{C}+(1-\alpha) \log (1-\alpha)-\frac{1-\alpha}{1-\sigma} \log (1-\sigma)$ is a constant term. Using $g_{h}=\bar{g}+(1-\rho \xi \Delta), g_{l}=\bar{g}-\rho \xi \Delta$, and $\bar{g}^{\prime}=-\alpha \rho(1-\rho) \Delta \frac{\omega+\xi \frac{\partial \omega}{\partial \xi}}{1+\alpha \rho(1-\rho) \xi \Delta \frac{\partial \omega}{\partial \bar{g}}}$, we obtain

$$
\begin{aligned}
\frac{d \log p}{d \xi} & =-\alpha \rho(1-\rho) \Delta \frac{\omega+\xi \frac{d \omega}{d \xi}}{\bar{z}_{I}+\rho(1-\rho) \xi \Delta \omega}-\frac{1-\alpha}{1-\sigma} \frac{\rho(1-\rho) \Delta\left[u_{h}^{\prime}-u_{l}^{\prime}\right]}{\rho u_{h}+(1-\rho) u_{l}}+ \\
& +\frac{1-\alpha}{1-\sigma} \frac{\alpha \rho(1-\rho) \Delta\left[\omega+\xi \frac{d \omega}{d \xi}\right]\left[\rho u_{h}^{\prime}+(1-\rho) u_{l}^{\prime}\right]}{\rho u_{h}+(1-\rho) u_{l}} \frac{1}{1+\alpha \rho(1-\rho) \xi \Delta \frac{\partial \omega}{\partial \bar{g}}} .
\end{aligned}
$$


By Proposition 2, $\frac{d \omega}{d \xi}<0$. Therefore, $\omega+\xi \frac{d \omega}{d \xi}<0$. Furthermore, in proving Lemma 1 we established that $\frac{\partial \omega}{\partial \bar{g}}>0$. These two conditions imply that

$$
\frac{1-\alpha}{1-\sigma} \frac{\alpha \rho(1-\rho) \Delta\left[\omega+\xi \frac{d \omega}{d \xi}\right]\left[\rho u_{h}^{\prime}+(1-\rho) u_{l}^{\prime}\right]}{\rho u_{h}+(1-\rho) u_{l}} \frac{1}{1+\alpha \rho(1-\rho) \xi \Delta \frac{\partial \omega}{\partial \bar{g}}}<0
$$

and $1+\alpha \rho(1-\rho) \xi \Delta \frac{\partial \omega}{\partial \bar{g}}>1$. Therefore we can conclude that

$$
\begin{aligned}
\frac{d \log p}{d \xi}> & -\alpha \rho(1-\rho) \Delta \frac{\omega+\xi \frac{d \omega}{d \xi}}{\bar{z}_{I}+\rho(1-\rho) \xi \Delta \omega}-\frac{1-\alpha}{1-\sigma} \frac{\rho(1-\rho) \Delta\left[u_{h}^{\prime}-u_{l}^{\prime}\right]}{\rho u_{h}+(1-\rho) u_{l}} \\
& +\frac{1-\alpha}{1-\sigma} \frac{\alpha \rho(1-\rho) \Delta\left[\omega+\xi \frac{d \omega}{d \xi}\right]\left[\rho u_{h}^{\prime}+(1-\rho) u_{l}^{\prime}\right]}{\rho u_{h}+(1-\rho) u_{l}} .
\end{aligned}
$$

Our strategy will be to prove that the expression on the right-hand side is positive.

With some work, such expression can be rewritten as

$$
\begin{aligned}
& -\alpha \rho(1-\rho) \Delta\left[\omega+\xi \frac{d \omega}{d \xi}\right] \frac{(1-\sigma)\left[\rho u_{h}+(1-\rho) u_{l}\right]-(1-\alpha)\left[\rho u_{h}^{\prime}+(1-\rho) u_{l}^{\prime}\right]\left[\bar{z}_{I}+\rho(1-\rho) \xi \Delta \omega\right]}{(1-\sigma)\left[\bar{z}_{I}+\rho(1-\rho) \xi \Delta \omega\right]\left[\rho u_{h}+(1-\rho) u_{l}\right]} \\
& -\frac{1-\alpha}{1-\sigma} \rho(1-\rho) \Delta \omega \frac{\rho u_{h}^{\prime}+(1-\rho) u_{l}^{\prime}}{\rho u_{h}+(1-\rho) u_{l}} .
\end{aligned}
$$

Since the last term is positive, a sufficient condition for $p$ to be increasing in $\xi$ is that

$$
\Gamma \equiv(1-\sigma)\left[\rho u_{h}+(1-\rho) u_{l}\right]-(1-\alpha)\left[\rho u_{h}^{\prime}+(1-\rho) u_{l}^{\prime}\right]\left[\bar{z}_{I}+\rho(1-\rho) \xi \Delta \omega\right] \geq 0 .
$$

Using $u(c)=\frac{c}{1-\sigma} u^{\prime}(c)$ and $\bar{g}=(1-\alpha) \bar{z}_{I}-\alpha \rho(1-\rho) \xi \Delta \omega$, we conclude that $\Gamma=0$.

\section{Ex-ante Heterogeneity}

In this section we extend the baseline model introduced in Section 3 to account for exante heterogeneity in entrepreneurs' abilities. This will introduce a new adjustment margin, as the cross-sectoral allocation of ability will now be a function of investor protection. This may relevant, as one may argue that this kind of selection effect is an important way in which investor protection affects economic development.

We assume that individuals differ with respect to their ability to succeed in the investment good sector. The probability of success is still the same for everyone. Agents differ in the payoffs, however. When successful, they obtain a payoff $x$. When unsuccessful, they obtain $x+\Delta$. For simplicity, we consider only two types of agents. A fraction $\psi$ has a productivity parameter $x_{g}$. The remainder has $x_{b}$, with $x_{g}>x_{b}$. All the other assumptions are the same as in Section 3. In particular, all agents have the same productivity when employed in the consumption good sector. Obviously, 
average productivity in the investment good sector is now type-dependent. We denote it as $\bar{z}_{I}(x)=x+\rho \Delta$.

Consistently with our analysis in Section 4, we require that along the equilibrium path all agents weakly prefer their occupational choices. Depending upon parameter values, at every time either one or both of the agents' types may be indifferent between the occupational choices. In what follows we restrict our attention to parameters that yield equilibria in which the relatively unproductive agents are indifferent between producing either good at all times, while relatively productive agents always strictly prefer the investment good sector.

Definition 2 Given an initial aggregate capital stock $K_{0}>0$, a competitive equilibrium with unproductive agents always indifferent between occupations is a nonnegative consumption level of the initial old $c_{0}^{o}$, non-negative contingent consumption allocations for young and old individuals in the investment good sector, $\left\{c_{h t}^{y}(x), c_{l t}^{y}(x)\right\}_{t=0}^{\infty}$ and $\left\{c_{h t}^{o}(x), c_{l t}^{o}(x)\right\}_{t=1}^{\infty}$, non-negative consumption allocations for young and old individuals in the consumption good sector $\left\{c_{t}^{y}\right\}_{t=0}^{\infty}$ and $\left\{c_{t}^{o}\right\}_{t=1}^{\infty}$, sequences of contracts $\left\{k_{I t}(x), \tau_{h t}(x), \tau_{l t}(x)\right\}_{t=0}^{\infty}$ and $\left\{k_{C t}, \tau_{C t}\right\}_{t=0}^{\infty}$, a fraction of unproductive individuals producing investment goods $\left\{N_{t}\right\}_{t=0}^{\infty}$, relative prices $\left\{p_{t}\right\}_{t=0}^{\infty}$, and interest rates $\left\{r_{t}\right\}_{t=0}^{\infty}$, such that

1. $c_{0}^{o}=p_{0} K_{0}\left(1+r_{0}\right)$ and at all $t \geq 0$.

2. for the entrepreneurs in the investment good sector and for $i=h, l$ and $t \geq 0$, $c_{i t}^{y}(x)=\tau_{i t}(x)-s\left(\tau_{i t}(x), r_{t+1}\right)$ and $c_{i t+1}^{o}(x)=s\left(\tau_{i t}(x), r_{t+1}\right)\left(1+r_{t+1}\right) ;$

3. for the entrepreneurs in the consumption good sector $c_{t}^{y}=\tau_{C t}-s\left(\tau_{C t}, r_{t+1}\right)$ and $c_{t}^{o}=s\left(\tau_{C t}, r_{t+1}\right)\left(1+r_{t+1}\right)$;

4. the scale in the consumption good sector is efficient, i.e. it solves problem (P1);

5. lending contracts are optimal, i.e. for all $t \geq 0$, they solve problem (P2);

6. $N_{t} \in[0,1]$

7. unproductive young individuals are indifferent between the two sectors:

$$
v\left(\tau_{C t}, r_{t+1}\right)=\rho v\left(\tau_{h t}\left(x_{b}\right), r_{t+1}\right)+(1-\rho) v\left(\tau_{l t}\left(x_{b}\right), r_{t+1}\right)
$$

8. productive young individuals are better off producing investment goods:

$$
\rho v\left(\tau_{h t}\left(x_{g}\right), r_{t+1}\right)+(1-\rho) v\left(\tau_{l t}\left(x_{g}\right), r_{t+1}\right) \geq v\left(\tau_{C t}, r_{t+1}\right)
$$


9. aggregate savings are equal to the value of the capital stock:

$$
\begin{aligned}
p_{t} K_{t+1} & =\psi\left[\rho s\left(\tau_{h t}\left(x_{g}\right), r_{t+1}\right)+(1-\rho) s\left(\tau_{l t}\left(x_{g}\right), r_{t+1}\right)\right] \\
& +(1-\psi) N_{t}\left[\rho s\left(\tau_{h t}\left(x_{b}\right), r_{t+1}\right)+(1-\rho) s\left(\tau_{l t}\left(x_{b}\right), r_{t+1}\right)\right] \\
& +(1-\psi)\left(1-N_{t}\right) s\left(\tau_{C t}, r_{t+1}\right)
\end{aligned}
$$

10. gross investment equals the production of investment goods:

$$
K_{t+1}=(1-\delta) K_{t}+\psi \bar{z}_{I}\left(x_{g}\right) k_{I t}^{\alpha}\left(x_{g}\right)+(1-\psi) N_{t} \bar{z}_{I}\left(x_{b}\right) k_{I t}^{\alpha}\left(x_{b}\right)
$$

11. the market for capital clears:

$$
K_{t}=\psi k_{I t}\left(x_{g}\right)+(1-\psi) N_{t} k_{I t}\left(x_{b}\right)+(1-\psi)\left(1-N_{t}\right) k_{C t} .
$$

The relative price of capital $p_{t}$ and the relative size $Q_{t}\left(x_{b}\right) \equiv k_{C t} / k_{I t}\left(x_{b}\right)$ are constant over time and are the solution to the system of non-linear equations

$$
p=\frac{z_{C}}{\bar{z}_{I}\left(x_{b}\right)+\rho(1-\rho) \xi \Delta \omega\left(x_{b}\right)} Q\left(x_{b}\right)^{\alpha-1},
$$

and

$$
p=\frac{(1-\alpha) z_{C}}{\left[\rho g_{h}\left(x_{b}\right)^{1-\sigma}+(1-\rho) g_{l}\left(x_{b}\right)^{1-\sigma}\right]^{1 /(1-\sigma)}} Q\left(x_{b}\right)^{\alpha} .
$$

The constants $g_{h}\left(x_{b}\right), g_{l}\left(x_{b}\right)$, and $\omega\left(x_{b}\right)$ are determined as in the proof of Proposition 1. It also follows that the comparative statics of $p$ and $Q\left(x_{b}\right)$ are unchanged. In particular, both $p$ and $Q\left(x_{b}\right)$ increase with $\xi$. Finally, the relative size $Q_{t}\left(x_{g}\right)$ is also constant over time and is determined by

$$
p=\frac{z_{C}}{\bar{z}_{I}\left(x_{g}\right)+\rho(1-\rho) \xi \Delta \omega\left(x_{g}\right)} Q\left(x_{g}\right)^{\alpha-1} .
$$

The relative average size is then given by

$$
\bar{Q}_{t} \equiv \frac{\left[\psi+(1-\psi) N_{t}\right] k_{C t}}{\psi k_{I t}\left(x_{g}\right)+(1-\psi) N_{t} k_{I t}\left(x_{b}\right)}=\frac{\psi+(1-\psi) N_{t}}{\psi / Q\left(x_{g}\right)+(1-\psi) N_{t} / Q\left(x_{b}\right)} .
$$

Analytical results are not easily forthcoming. However, numerical results show that the qualitative effect of poorer protection on the relative price and on the investment rate are the same as those described in Section 6. Whether $\bar{Q}_{t}$ increases as investor protection deteriorates, depends on the response of $Q\left(x_{g}\right)$ to changes in $\xi$. Numerical analysis shows that for certain parameter values $Q\left(x_{g}\right)$ does indeed decrease with $\xi$, and so does $\bar{Q}_{t}$.

Further analysis reveals that the impact of poor protection on $\bar{Q}_{t}$ depends on risk-aversion. Figure 10 gives a qualitative rendering of the schedules $F O C\left(x_{b}\right)$, 


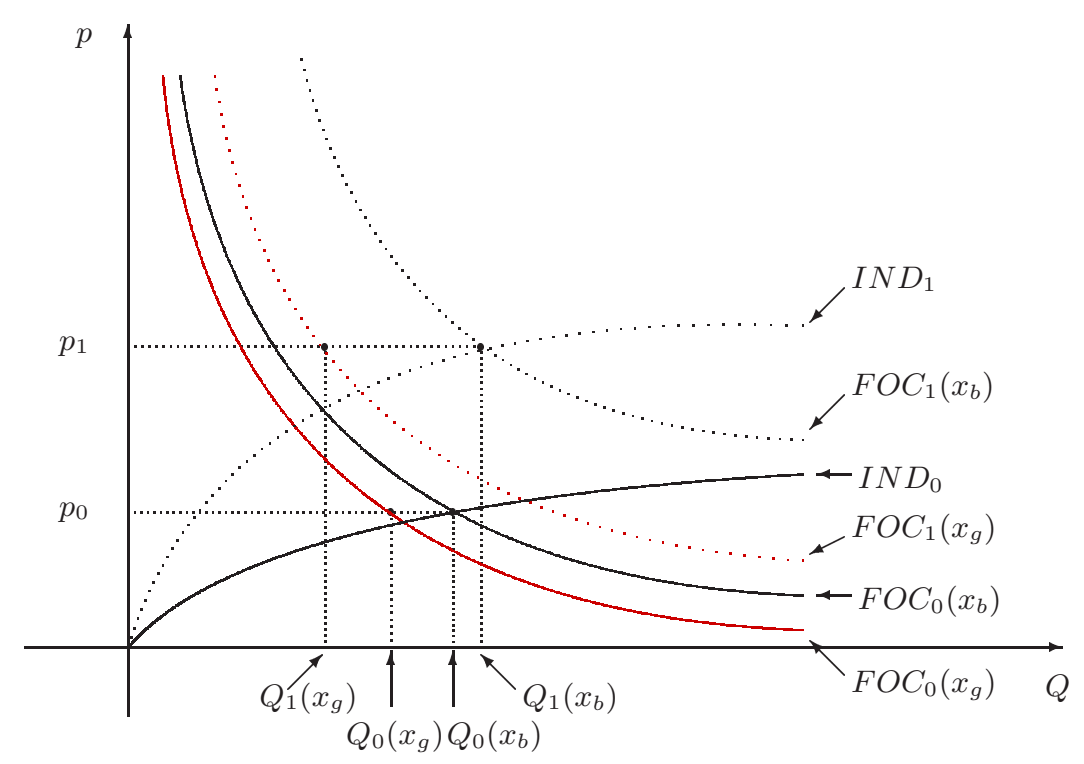

Figure 10: Comparative statics with respect to $\xi$.

$F O C\left(x_{g}\right)$, and $I N D$, with high $(\xi=0)$ and low protection $(\xi=1)$, respectively. In Section 4.2 we justified the shape and direction of change of the schedules. For the sake of completeness, here we add that the $F O C\left(x_{b}\right)$ schedule lies everywhere lower than $F O C\left(x_{b}\right)$ because both $\bar{z}_{I}\left(x_{g}\right)>\bar{z}_{I}\left(x_{g}\right)$ and $0>\omega\left(x_{g}\right)>\omega\left(x_{b}\right)$. The term $\omega$ is increasing in $x$ because of non-increasing absolute risk-aversion: a given spread between contingent transfers induces a smaller utility cost when the average transfer is higher.

Let's now get to the effect of risk-aversion on the comparative statics of $\bar{Q}_{t}$. Since our preferences display nonincreasing risk-aversion, an increase in $\xi$ has a higher impact on the factor $\omega\left(x_{b}\right)$ than on $\omega\left(x_{g}\right)$. As a consequence, the upward shift in $F O C\left(x_{b}\right)$ is always greater. How greater, depends on the coefficient of relative risk aversion. A higher value of $\sigma$, by increasing the gap between the absolute risk-aversion coefficients of the two types, also implies a larger gap between the schedules $F O C_{1}\left(x_{b}\right)$ and $F O C_{1}\left(x_{g}\right)$. In turn, this means a higher chance that $Q_{1}\left(x_{h}\right)<Q_{0}\left(x_{h}\right)$.

\section{E The model with a continuum of states}

In this appendix we analyze in detail the model with a continuum of states introduced in Section 5. We start by considering the case of no exogenous growth (i.e., $\gamma=1$ ). We assume that, in both sectors, $z \in Z \equiv\left(z_{\min },+\infty\right), z_{\text {min }} \geq 0$. In sector $j, j=I, C$, $z$ is distributed according to the cumulative distribution function $F_{j}(z)$, which admits density function $f_{j}(z)$ and first moment $\bar{z}_{j}$. 
The contracting problem in the investment good sector writes as follows (the problem in the consumption good sector is entirely analogous):

$$
\begin{array}{cc} 
& \max _{k_{I t}, \tau_{I t}(z)} \int_{Z} u\left[\tau_{I t}(z)\right] f_{I}(z) d z, \\
\text { subject to } & u\left[\tau_{I t}(z)\right] \geq u\left[\tau_{I t}\left(z^{\prime}\right)+\xi p_{t}\left(z-z^{\prime}\right) k_{I t}^{\alpha}\right] \forall z, z^{\prime}, z \geq z^{\prime}, \\
& \bar{\tau}_{I t} \equiv \int_{Z} \tau_{I t}(z) f_{I}(z) d z=p_{t} \bar{z}_{I} k_{I t}^{\alpha}-\left(r_{t}+\delta\right) p_{t} k_{I t} .
\end{array}
$$

By monotonicity and strict concavity of the utility function, the incentive compatibility constraint (35) implies $\tau_{I t}(z)=\tau_{I t}\left(z^{\prime}\right)+\xi p_{t}\left(z-z^{\prime}\right) k_{I t}^{\alpha} \forall z, z^{\prime}, z \geq z^{\prime}$. Then, simply by the definition of $\bar{\tau}_{I t}$, it follows that $\forall z, \tau_{I t}(z)=\bar{\tau}_{I t}+\xi p_{t}\left(z-\bar{z}_{I}\right) k_{I t}^{\alpha}$. Finally, this implies that the above program collapses to

$$
\begin{aligned}
& \max _{k_{I t}, \bar{\tau}_{I t}} \int_{Z} u\left[\bar{\tau}_{I t}+\xi p_{t}\left(z-\bar{z}_{I}\right) k_{I t}^{\alpha}\right] f_{I}(z) d z, \\
& \text { subject to } \bar{\tau}_{I t}=p_{t}\left[\bar{z}_{I} k_{I t}^{\alpha}-\left(r_{t}+\delta\right) k_{I t}\right] .
\end{aligned}
$$

The necessary and sufficient condition for this problem is the generalization of condition (19):

$$
r_{t}+\delta=\alpha k_{I t}^{\alpha-1}\left[\bar{z}_{I}+\xi \frac{\int_{Z} u^{\prime}\left[\tau_{I t}(z)\right]\left(z-\bar{z}_{I}\right) f_{I}(z) d z}{\int_{Z} u^{\prime}\left[\tau_{I t}(z)\right] f_{I}(z) d z}\right] .
$$

We can follow the argument of Proposition 1 to show that, subject to a restriction on the value of $z_{m i n}$, the transfer function takes the form $\tau_{I t}(z)=g_{I}(z) p_{t} k_{I t}^{\alpha}$, where $g_{I}: Z \rightarrow \Re^{+}$is the solution to the following functional equation:

$$
g_{I}(z)=\bar{z}_{I}(1-\alpha-\xi)-\alpha \xi \frac{\int_{Z} u^{\prime}\left[g_{I}(z)\right]\left(z-\bar{z}_{I}\right) f_{I}(z) d z}{\int_{Z} u^{\prime}\left[g_{I}(z)\right] f_{I}(z) d z}+\xi z .
$$

Now let $x$ denote a random variable distributed over $(0,+\infty)$ with distribution $F_{I}(z-$ $\left.z_{\min }\right)$. Then we can show that necessary and sufficient condition for equation (37) to admit a solution is that $\xi \leq \frac{\bar{z}_{I}+z_{\min }}{\bar{z}_{I}+\frac{\alpha}{1-\alpha} \frac{E\left(x^{1-\sigma}\right)}{E\left(x^{-\sigma}\right)}}$, provided that the two expectations exist. In turn, this implies that a solution to (37) exists for all $\xi \in[0,1]$, if and only if $z_{\min } \geq \frac{\alpha}{1-\alpha} \frac{E\left(x^{1-\sigma}\right)}{E\left(x^{-\sigma}\right)}$. In Section 5 we have assumed that $\log \left(z-z_{\min }\right)$ is normally distributed with mean $\mu_{I}$ and variance $\eta_{I}^{2}$. In that case, the condition rewrites as $z_{\text {min }} \geq \frac{\alpha}{1-\alpha} e^{\mu_{I}+\frac{1}{2} \eta_{I}^{2}(1-2 \sigma)}$.

Then, under the condition that $z_{m i n} \geq \frac{\alpha}{1-\alpha} e^{\max \left[\mu_{C}+\frac{1}{2} \eta_{C}^{2}(1-2 \sigma), \mu_{I}+\frac{1}{2} \eta_{I}^{2}(1-2 \sigma)\right]}$, solving for the competitive equilibrium is rather simple. Let $\widetilde{\omega}_{j} \equiv \frac{\int_{Z} u^{\prime}\left[g_{j}(z)\right]\left(z-\bar{z}_{j}\right) f_{j}(z) d z}{\int_{Z} u^{\prime}\left[g_{j}(z)\right] f_{j}(z) d z}$ for $j=I, C$. As it was the case for the simpler version of the model introduced in 
Section $3, Q_{t}$ and $p_{t}$ turn out to be time-invariant. They can be expressed as

$$
\begin{aligned}
Q & =\frac{\bar{z}_{C}+\xi \widetilde{\omega}_{C}}{\bar{z}_{I}+\xi \widetilde{\omega}_{I}}\left[\frac{E\left[u\left(g_{I}(z)\right)\right]}{E\left[u\left(g_{C}(z)\right)\right]}\right]^{\frac{1}{1-\sigma}} \\
\text { and } \quad p & =\left[\frac{\bar{z}_{C}+\xi \widetilde{\omega}_{C}}{\bar{z}_{I}+\xi \widetilde{\omega}_{I}}\right]^{\alpha}\left[\frac{E\left[u\left(g_{C}(z)\right)\right]}{E\left[u\left(g_{I}(z)\right)\right]}\right]^{\frac{1-\alpha}{1-\sigma}} .
\end{aligned}
$$

For given $K_{0}$, the competitive equilibrium allocation is characterized by imposing that the capital stock (expressed in units of consumption good) at $t+1$ is equal to saving at time $t$ :

$$
p K_{t+1}=\kappa\left(r_{t+1}\right) k_{I t}^{\alpha}\left[p N_{t} E\left(g_{I}(z)\right)+\left(1-N_{t}\right) Q^{\alpha} E\left(g_{C}(z)\right)\right],
$$

the capital stock at $t+1$ is equal to the capital at time $t$ plus net investment at time $t$ :

$$
K_{t+1}=(1-\delta) K_{t}+N_{t} \bar{z}_{I} k_{t}^{\alpha},
$$

the capital stock at time $t$ is equal to the sum of the capital utilized in the two sectors:

$$
K_{t}=N_{t} k_{I t}+\left(1-N_{t}\right) k_{C t},
$$

and that the necessary and sufficient condition for the contracting problem in the capital good sector is satisfied:

$$
r_{t}+\delta=\alpha k_{I t}^{\alpha-1}\left[\bar{z}_{I}+\xi \widetilde{\omega}_{I}\right]
$$

It is now straightforward to amend this model to allow for exogenous growth. We simply assume that in sector $j, \log \left(z-\gamma^{t} z_{\text {min }}\right) \sim N\left(\mu_{j}, \eta_{j}^{2}\right)$. This economy converges to a balanced-growth steady-state where the interest rate $r_{t}$, the fraction of entrepreneurs in the investment good sector $N_{t}$, the relative price $p_{t}$, and $Q_{t}$ are all constant, while the remaining variables grow at the constant rate $\gamma^{\frac{1}{1-\alpha}}$. In particular, the equilibrium values of $p$ and $Q$ do not depend on the growth rate of the economy. Transfers in sector $C$ at time $t$ are given by $\tau_{C t}(z)=g_{C t}(z) k_{C t}^{\alpha}=\gamma^{t} g_{C 0}(z) k_{C t}^{\alpha}$. Similarly for sector $I$.

Now define $\widehat{K}_{t}=\gamma^{-\frac{1}{1-\alpha} t} K_{t}$. Then, for given initial capital stock $K_{0}$, the competitive equilibrium paths of $\widehat{K}_{t}, \widehat{k}_{I t}, \widehat{k}_{C t}, N_{t}$, and $r_{t}$ are characterized by simple transformations of equations (38)-(41):

$$
\begin{aligned}
p \widehat{K}_{t+1} \gamma^{\frac{1}{1-\alpha}} & =\kappa\left(r_{t+1}\right) \widehat{k}_{I t}^{\alpha}\left[p N_{t} E\left(g_{I 0}(z)\right)+\left(1-N_{t}\right) Q^{\alpha} E\left(g_{C 0}(z)\right)\right] \\
\widehat{K}_{t+1} \gamma^{\frac{1}{1-\alpha}} & =(1-\delta) \widehat{K}_{t}+N_{t} \bar{z}_{I} \widehat{k}_{t}^{\alpha} \\
\widehat{K}_{t} & =N_{t} \widehat{k}_{I t}+\left(1-N_{t}\right) \widehat{k}_{C t} \\
r_{t}+\delta & =\alpha \widehat{k}_{I t}^{\alpha-1}\left[\bar{z}_{I}+\xi \widetilde{\omega}_{I}\right] .
\end{aligned}
$$




\section{References}

Aghion, P., And P. Howitt (1992): "A Model of Growth through Creative Destruction," Econometrica, 60, 323-51.

Albuquerque, R., And N. Wang (2004): "An Agency-Based Asset Pricing Model," Boston University and Columbia.

Atkeson, A., And P. Kehoe (2005): "Modeling and Measuring Organizational Capital," Journal of Political Economy, 113, 1026-1053.

Buera, F. (2003): "A Dynamic Model of Entrepreneurship with Borrowing Constraints," Northwestern University.

Burstein, A., and A. Monge-Naranjo (2005): "Aggregate Consequences of International Firms in Developing Countries," UCLA and Northwestern University.

Caselli, F., And N. Gennaioli (2003): "Dynastic Management," NBER working paper \# 9442 .

Castro, R., G. L. Clementi, and G. MacDonald (2003): "Investor Protection, Optimal Incentives, and Economic Growth," Working paper no. s-mf-03-19, salomon center for the study of financial institutions.

(2004): "Investor Protection, Optimal Incentives, and Economic Growth," Quarterly Journal of Economics, 119(3), 1131-1175.

Chari, V., P. Kehoe, and E. McGrattan (1996): "The Poverty of Nations: A Quantitative Exploration," NBER Working Paper \# 5414.

Comin, D., and T. Philippon (2005): "The Rise in Firm-Level Volatility: Causes and Consequences," NBER Macroeconomics Annual, 20.

Davis, S. J., J. Haltiwanger, R. Jarmin, and J. Miranda (2006): "Volatility and Dispersion in Business Growth Rates: Publicly Traded versus Privately Held Firms," NBER Working Papers 12354, National Bureau of Economic Research, Inc.

De Long, B., And L. Summers (1991): "Equipment Investment and Economic Growth," Quarterly Journal of Economics, pp. 445-502.

Easterly, W. (1993): "How Much Do Distorsions Affect Growth?," Journal of Monetary Economics, 32, 187-212. 
Eaton, J., And S. Kortum (2001): "Trade in Capital Goods," European Economic Review, 45, 1195-1235.

Erosa, A., and A. Hidalgo-Cabrillana (2004): "On Capital Market Imperfections as A Source of Low TFP and Economic Rents," University of Toronto.

Evans, D. (1987): "The Relationship between Firm Growth, Size and Age: Estimates for 100 Manufacturing Firms," Journal of Industrial Economics, 35, 567-81.

FABBrI, D. (2004): "Law Enforcement, Firms, and Capital Accumulation: Theory and Evidence," HEC - University of Lausanne.

Grossman, G., and E. Helpman (1991): "Quality Ladders and Product Cycles," Quarterly Journal of Economics, 106, 557-586.

Guner, N., G. Ventura, And X. Yi (2005): "Macroeconomic Implications of SizeDependent Policies," Pennsylvania State University.

Hall, B. (1987): "The Relationship between Firm Size and Firm Growth in the US Manufacturing Sector," Journal of Industrial Economics, 35, 583-606.

Hall, R., And C. Jones (1999): "Why Do Some Countries Produce So Much More Output Per Worker Than Others?," Quarterly Journal of Economics, 114, 83-116.

Harvey, A. (1976): "Estimating Regresssion Models with Multiplicative Heteroscedasticity," Econometrica, 44, 461-465.

Heston, A., And R. Summers (1988): "What we have learned about prices and quantities from international comprisons: 1987," American Economic Review, 78, $467-73$.

(1991): “The Penn World Table (Mark 5): An Expanded Set of International Comparisons, 1950-1988," Quarterly Journal of Economics, 106, 327-68.

- (1996): "International price and quantity comparisons: potentials and pitfalls," American Economic Review, 86, 20-24.

Heston, A., R. Summers, and B. Aten (2002): Penn World Table Version 6.1. Center for International Comparisons at the University of Pennsylvania (CICUP), Philadelphia, PA.

Hsieh, C.-T., And P. Klenow (2003): "Relative Prices and Relative Prosperity," NBER Working Paper \# 9701. 
Jones, C. (1994): "Economic Growth and The Relative Price of Capital," Journal of Monetary Economics, 34, 359-82.

Klenow, P. (1996): "Industry Innovation: Where and Why," Carnegie-Rochester Conference Series on Public Policy, 44, 125-150.

Klenow, P., And A. Rodriguez-Clare (1997): "The Neoclassical Revival in Growth Economics: Has It Gone Too Far?," NBER Macroeconomics Annual, 12, 73-103.

Kydland, F., and E. Prescott (1990): "Business Cycles: Real Facts and a Monetary Myth," Federal Reserve Bank of Minneapolis Quarterly Review, 14, 3-18.

La Porta, R., F. Lopez-de Silanes, A. Shleifer, and R. Vishny (1998): "Law and Finance," Journal of Political Economy, 106, 1113-55.

Lacker, J., And J. Weinberg (1989): "Optimal Contracts under Costly State Falsification," Journal of Political Economy, 97, 1345-63.

Mankiw, G., D. Romer, and D. Weil (1992): "A Contribution to The Empirics of Economic Growth," Quarterly Journal of Economics, pp. 407-37.

Rajan, R. G., and L. Zingales (1998): "Financial Dependence and Growth," American Economic Review, 88, 559-586.

Restuccia, D. (2004): "Barriers to Capital Accumulation and Aggregate Total Factor Productivity," International Economic Review, 45, 225-38.

Restuccia, D., And R. Rogerson (2003): "Policy Distortions and Aggregate Productivity with Heterogeneous Plants," Arizona State University.

Restuccia, D., and C. Urrutia (2001): "Relative Prices and Investment Rates," Journal of Monetary Economics, 47, 93-121.

Shleifer, A., And D. Wolfenzon (2002): "Investor Protection and Equity Markets," Journal of Financial Economics, 66, 3-27. 